\title{
Genetic Analyses of the FRNK Motif Function of Turnip mosaic virus Uncover Multiple and Potentially Interactive Pathways of Cross-Protection
}

\author{
Yi-Jung Kung, ${ }^{1,2}$ Pin-Chun Lin, ${ }^{3}$ Shyi-Dong Yeh, ${ }^{2,4}$ Syuan-Fei Hong, ${ }^{5}$ Nam-Hai Chua, ${ }^{1}$ Li-Yu Liu, ${ }^{6}$ \\ Chan-Pin Lin, ${ }^{3,7}$ Yu-Hsin Huang, ${ }^{3,7}$ Hui-Wen Wu, ${ }^{1}$ Chin-Chih Chen, ${ }^{8}$ and Shih-Shun Lin ${ }^{3,9,10}$
}

${ }^{1}$ The Plant Molecular Biology, The Rockefeller University, 1230 York Ave, New York 10065, U.S.A.; ${ }^{2}$ Department of Plant Pathology, National Chung-Hsing University, 250 Kao-Kung Rd., Taichung, Taiwan; ${ }^{3}$ Institute of Biotechnology, National Taiwan University, 81, Chang-Xing St., Taipei, Taiwan; ${ }^{4} \mathrm{NCHU}-U \mathrm{CD}$ Plant and Food Biotechnology Center, National ChungHsing University, Taichung, Taiwan; ${ }^{5}$ Department of Horticulture and Landscape Architecture, ${ }^{6}$ Department of Agronomy, and ${ }^{7}$ Department of Plant Pathology and Microbiology, National Taiwan University, 1, Sec 4, Roosevelt Rd., Taipei, Taiwan; ${ }^{8}$ Division of Plant Pathology, Agricultural Research Institute, Wu-Feng, Taichung Taiwan; ${ }^{9}$ Genome and Systems Biology Degree Program, National Taiwan University, Taipei, Taiwan; ${ }^{10}$ Agricultural Biotechnology Research Center, Academia Sinica, 128 Academia Rd, Sec. 2, Taipei, Taiwan

Submitted 22 April 2014. Accepted 25 April 2014.

Cross-protection triggered by a mild strain of virus acts as a prophylaxis to prevent subsequent infections by related viruses in plants; however, the underling mechanisms are not fully understood. Through mutagenesis, we isolated a mutant strain of Turnip mosaic virus (TuMV), named TuGK, that contains an Arg182Lys substitution in helper component-proteinase $\left(\mathrm{HC}-\mathrm{Pro}^{\mathrm{K}}\right)$ that confers complete cross-protection against infection by a severe strain of TuMV in Nicotiana benthamiana, Arabidopsis thaliana Col0, and the Arabidopsis dcl2-4/dcl4-1 double mutant defective in DICER-like ribonuclease (DCL)2/DCL4-mediated silencing. Our analyses showed that ${\mathrm{HC}-\text { Pro }^{\mathrm{K}}}$ loses the ability to interfere with microRNA pathways, although it retains a partial capability for RNA silencing suppression triggered by DCL. We further showed that Tu-GK infection triggers strong salicylic acid (SA)-dependent and SAindependent innate immunity responses. Our data suggest that DCL2/4-dependent and -independent RNA silencing pathways are involved, and may crosstalk with basal innate immunity pathways, in host defense and in crossprotection.

Cross-protection results from a primary infection with a mild virus (termed the protective virus) that confers resistance against secondary infections by severe viruses (termed challenge viruses) that share sequence homology with the

\section{Y.-J. Kung, P.-C. Lin, and S.-D. Yeh contributed equally to this work.}

The raw small RNA reads reported in this article are available in the National Center for Biotechnology Information Short Read Archive under accession numbers SRR1262389 (Tu-GR/Col-0), SRR1262545 (TuGK/Col-0), SRR1262546 (Tu-GR/dcl2/4), and SRR1262601 (Tu$\mathrm{GK} / d c l 2 / 4)$.

Corresponding author: S.-S. Lin; Telephone: +886-2-33666023; Fax: +886-2-33666001; E-mail: linss01@ntu.edu.tw

* The $\boldsymbol{e}$-Xtra logo stands for "electronic extra" and indicates that one supplementary figure is published online.

(C) 2014 The American Phytopathological Society protective virus (Gal-On and Shiboleth 2006; Lin et al. 2007a and b; McKinney 1929). The features of cross-protection resemble the feature of current defense models for plants. First, cross-protection shares biochemical similarities to post-transcriptional gene silencing (PTGS), which has been regarded as a mechanism of RNA-mediated resistance that is produced via a transgenic plant approach (English et al. 1996; Prins and Goldbach 1996). However, the protective virus must persist in the host to trigger cross-protection, implying that cross-protection is not identical to RNA-mediated resistance, which can completely eliminate an invading virus by PTGS (Ratcliff et al. 1997; Simón-Mateo and García 2011). Second, the protective virus in the host plant provides protein-mediated resistance through interference with the uncoating of the challenge virus (Lu et al. 1988; Osbourn et al. 1990; Register and Beachy 1988), functional interference by a dominant negative effect, such as truncated replicase (Hellwald and Palukaitis 1995; Nguyen et al. 1996), or sequestration of key host factors that are essential for the replication and spreading of the challenge virus (Hofius et al. 2007; Lellis et al. 2002; Ziebell and Carr 2010). Third, the innate immune mechanisms of a host plant, such as the salicylic-acid (SA)-associated defense response that is triggered during viral infections, provide a basal defensive reaction against pathogens that do not have viral sequence- or speciesspecific resistance (Jovel et al. 2011; Kim et al. 2008; Love et al. 2012; Zhu et al. 2011). Although various defense models have been proposed, none of the models fully explain crossprotection; therefore, the mechanism of cross-protection remains unclear.

RNA-mediated resistance is based on the sense-PTGS mechanism of protecting the host against RNA-virus infection (Bouché et al. 2006; Ruiz et al. 1998; Simón-Mateo and García 2011; Wang et al. 2011b). The replicating viral RNA has a doublestranded structure and is regarded as a pathogen-associated molecular pattern that can initiate antiviral silencing and be cleaved by DICER-like ribonuclease 2 (DCL2) and DCL4 into fragments of 22 and 21 nucleotides (nt) of primary viralderived short-interfering RNAs (vsiRNAs), respectively (Nakahara et al. 2012). Garcia-Ruiz and associates (2010) demonstrated that DCL4 is important for antiviral silencing in 
inoculated leaves, whereas DCL2 and DCL4 are involved in silencing in systemic leaves or inflorescences. In addition, the plant loss-of-function mutants $d c l 2$ and $d c l 4$ are more susceptible to virus infection (Bouché et al. 2006; Deleris et al. 2006; Wang et al. 2011b). These primary vsiRNAs induce the host RNA-dependent RNA polymerases and other host components to generate secondary vsiRNA to amplify and maintain the antiviral silencing response (Bouché et al. 2006; Deleris et al. 2006; Eamens et al. 2008; Garcia-Ruiz et al. 2010; Wang et al. 2011b). Specifically, the vsiRNAs are loaded into ARGONAUTE1 (AGO1), which is a core protein of the RNAinduced silencing complex (RISC), to form a vsiRISC that targets viral RNAs. Due to the sequence identity of vsiRNAs, vsiRISC has a strain specificity that targets and cleaves the RNA genome of the second invading virus that shares sequence homology (Morel et al. 2002).

To counteract the host defensive response, plant viruses encode various viral suppressors to repress host RNA silencing (Gal-On and Shiboleth 2006; Simón-Mateo and García 2011; Ziebell and Carr 2010). For example, the helper componentproteinase (HC-Pro) of the genus Potyvirus and $2 \mathrm{~b}$ of Cucumber mosaic virus (CMV) inhibit DCL2- and DCL4-mediated PTGS (Lin et al. 2007b; Ziebell et al. 2007). Specific mutations in these viral suppressors lead to mild viral symptoms with lower viral titers in the infected plants, implying that the capability of viral suppressors to antagonize the DCL2- and DCL4-mediated PTGS may be affected (Lin et al. 2007b; Ziebell et al. 2007).

Previous studies demonstrated that the highly conserved Arg180 of the FRNK motif of HC-Pro of the Zucchini yellow mosaic virus (ZYMV) is essential for viral pathogenicity (GalOn 2000; Lin et al. 2007b). The ZYMV mild strain of Taiwan isolate (GAC) and Israel isolate (AG), which has an Arg180Ile mutation of the FRNK motif, causes mild symptoms with moderate viral titer in infected zucchini squash plants and confers complete cross-protection (Gal-On 2000; Lin et al. 2007b). In addition, the Arg of the FRNK motif of HC-Pro is also essential for the suppression of the microRNA (miRNA)mediated host response that regulates several genes during plant development (Shiboleth et al. 2007; Wu et al. 2010). These results indicated that the Arg of the FRNK motif of HCPro plays an important role in mild strain-mediated cross-protection.

In this study, we used the Turnip mosaic virus (TuMV) severe strain YC5 carrying a green fluorescent protein (GFP) gene as a model virus (denoted as Tu-GR) (Chen et al. 2003; Niu et al. 2006) to generate attenuated mutants to further investigate mechanisms of cross-protection. Nineteen mutants with different amino acid substitutions of Arg182 of the FRNK motif were screened. Mutant Tu-GK, which contains an Arg182Lys substitution in HC-Pro (HC-Pro ${ }^{\mathrm{K}}$ ) and causes symptomless infection in Arabidopsis thaliana Col-0 plants and moderate infection in the Arabidopsis dcl2/4 mutant plants, was selected for detailed functional analyses in crossprotection. Our results indicated that Tu-GK provided complete cross-protection against Tu-GR infection in both Col-0 and $d c l 2 / 4$ mutant plants. $\mathrm{HC}$-Pro ${ }^{\mathrm{K}}$ lost the ability to interfere with the miRNA pathway, resulting in infection without conspicuous symptoms, although it retained partial capability for RNA silencing suppression triggered by DCL. We found that DCL2/DCL4-independent vsiRNAs existed in $d c l 2 / 4$ plants. In addition, the DCL2/DCL4-mediated gene silencing pathway crosstalk with basal innate immunity pathways mediated by SA-dependent pathway and SA-independent pathway. Our results raise the intriguing possibility that multiple and likely cooperative mechanisms of resistance are involved in viral cross-protection.

\section{RESULTS}

Mutagenesis identified a TuMV strain that conferred effective cross-protection in Nicotiana benthamiana.

A useful and effective viral strain for mechanistic studies of cross-protection should sustain a moderate titer for a long period of time in an infected plant and does not cause severe disease symptoms. To identify such a TuMV strain, we used mutagenesis targeting the highly conserved Arg in the FRNK motif of HC-Pro that is essential for Potyvirus pathogenicity (Fig. 1A, upper panel) (Gal-On 2000; Lin et al. 2007a and b). In TuMV, the conserved Arg is at position 182 (Fig. 1A, upper panel). Nineteen amino acid substitutions were generated for Arg182 in the severe strain YC5 background, which carries a GFP gene (denoted as Tu-GR) (Chen et al. 2003; Niu et al. 2006) (Fig. 1A, lower panel). These mutants were named Tu-GX, where $\mathrm{X}$ is the one-letter abbreviation of the introduced amino acid (Fig. 1A, lower panel). All mutants were evaluated for their infectivity and pathogenicity in Nicotiana benthamiana, which is relatively easy to inoculate, to select for a mild TuMV strain that would confer cross-protection for further mechanistic studies in Arabidopsis. Upon inoculation onto N. benthamiana, only nine of the mutants (Tu-GH, Tu-GK, Tu-GS, TuGT, Tu-GP, Tu-GA, Tu-GI, Tu-GF, and Tu-GY) showed infectivity (Fig. 1A, lower panel).

Based on their titers and severity of the symptoms they caused in the infected $N$. benthamiana plants, the nine infectious TuMV mutants as well as the wild-type virus could be classified into four types. Type I included Tu-GR, the wild type, which caused mosaic and leaf distortion symptoms with strong GFP fluorescence under UV illumination (Fig. 1A and B). Furthermore, it accumulated to high titers (indirect enzymelinked immunosorbent assay [ELISA] reading at an optical density at $405 \mathrm{~nm}\left[\mathrm{OD}_{405}\right]$ of 1.2 to 1.6$)$ from 5 to 15 days postinoculation (dpi) (Fig. 1D). Type II included Tu-GF, TuGP, and Tu-GY. They caused necrotic symptoms in the inoculated leaves and curling of systemic leaves with detectable GFP fluorescence (Fig. 1A and C). Their titers varied during infection, suggesting unstable viral accumulations (Fig. 1D). Type III included Tu-GH, Tu-GK, and Tu-GT. They induced mild mottling in the inoculated leaves and no symptoms in systemic leaves, with low GFP fluorescence in systemic leaves (Fig. 1A and C). Although Tu-GH had a low titer $\left(\mathrm{OD}_{405}<\right.$ $0.5)$, Tu-GK and Tu-GT showed a stable middle range of titers compared with that of Tu-GR (Fig. 1D). However, the Tu-GK titer had a shorter recovery time $(<5 \mathrm{dpi})$ than Tu-GH $(>10$ dpi) during infection (Fig. 1D). Type IV (Tu-GI, Tu-GS, and Tu-GA) did not cause conspicuous symptoms and exhibited very low GFP fluorescence (Fig. 1A and C). These strains had low titers $\left(\mathrm{OD}_{405}<0.5\right)$ (Fig. 1D).

The type II mutants caused severe symptoms in inoculated and systemic leaves and type IV mutants showed relatively constant low titers that were difficult to sustain in the host plant. Moreover, none of the type IV mutants provided effective cross-protection in $N$. benthamiana against Tu-GR (data not shown). Therefore, they were not suitable as protective viruses for cross-protection studies. For the type III mutants, Tu-GH had a very low titer and Tu-GT required an excessively long recovery time. They were not suitable for cross-protection studies either. In contrast, Tu-GK caused mild mottling symptoms in the inoculated leaves and no symptoms in systemic leaves after $10 \mathrm{dpi}$ (Fig. 1C). It was stably sustained in the host with a moderate viral titer compared with Tu-GR (Fig. 1D). Moreover, Tu-GK provided effective cross-protection in $N$. benthamiana plants against Tu-GR (Supplementary Fig. S1). Therefore, the Tu-GK mutant was selected for further studies on cross-protection in Arabidopsis. 
A

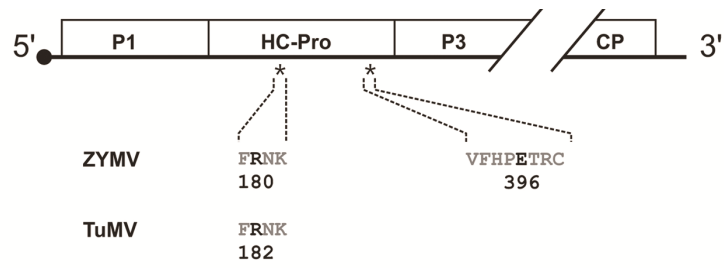

\begin{tabular}{|c|c|c|c|c|c|c|c|c|}
\hline P1 & \multicolumn{2}{|c|}{ HC-Pro } & & CIP & \begin{tabular}{l|l|} 
VPg & Nla \\
\end{tabular} & $\mathrm{Nlb}$ & GFP & $\mathrm{CP}$ \\
\hline \multicolumn{9}{|c|}{182} \\
\hline & $\star$ & Name & $N$. & \multicolumn{2}{|c|}{ benthamiana } & TYPE & & \\
\hline & RNK & Tu-GR & \multicolumn{3}{|c|}{+} & I & & \\
\hline & F. . & Tu-GF & & \multicolumn{2}{|l|}{+} & II & & \\
\hline & P. . & Tu-GP & & \multicolumn{2}{|l|}{+} & II & & \\
\hline & Y. . & Tu-GY & & \multicolumn{2}{|l|}{+} & II & & \\
\hline & н. . & $\mathrm{Tu}-\mathrm{GH}$ & \multicolumn{3}{|c|}{+} & III & & \\
\hline & $\mathrm{K}$. . & Tu-GK & \multicolumn{3}{|c|}{+} & III & & \\
\hline & T. . & $\mathrm{Tu}-\mathrm{GT}$ & \multicolumn{3}{|c|}{+} & III & & \\
\hline & I. . & Tu-GI & \multicolumn{3}{|c|}{+} & IV & & \\
\hline & s. . & Tu-GS & & \multicolumn{2}{|l|}{+} & IV & & \\
\hline & A. . & $\mathrm{Tu}-\mathrm{GA}$ & \multicolumn{3}{|c|}{+} & IV & & \\
\hline- & ---1 & ---- & & - & -- & --- & -- & -- \\
\hline & D. . & $\mathrm{Tu}-\mathrm{GD}$ & \multicolumn{3}{|c|}{-} & & & \\
\hline & E. . & $\mathrm{Tu}-\mathrm{GE}$ & \multicolumn{3}{|c|}{ - } & & & \\
\hline & N. . & $\mathrm{Tu}-\mathrm{GN}$ & \multicolumn{3}{|c|}{-} & & & \\
\hline & Q. . & $\mathrm{Tu}-\mathrm{GQ}$ & \multicolumn{3}{|c|}{-} & & & \\
\hline & c.. & $\mathrm{Tu}-\mathrm{GC}$ & & - & & & & \\
\hline & G. . & Tu-GG & & - & & & & \\
\hline & v. . & Tu-GV & & - & & & & \\
\hline & L. . & Tu-GL & & - & & & & \\
\hline & M. . & Tu-GM & & - & & & & \\
\hline & w. . & Tu-GW & & - & & & & \\
\hline
\end{tabular}

B White light

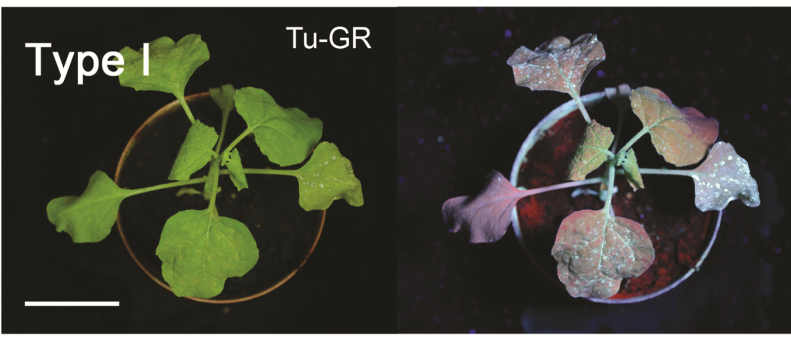

C White light
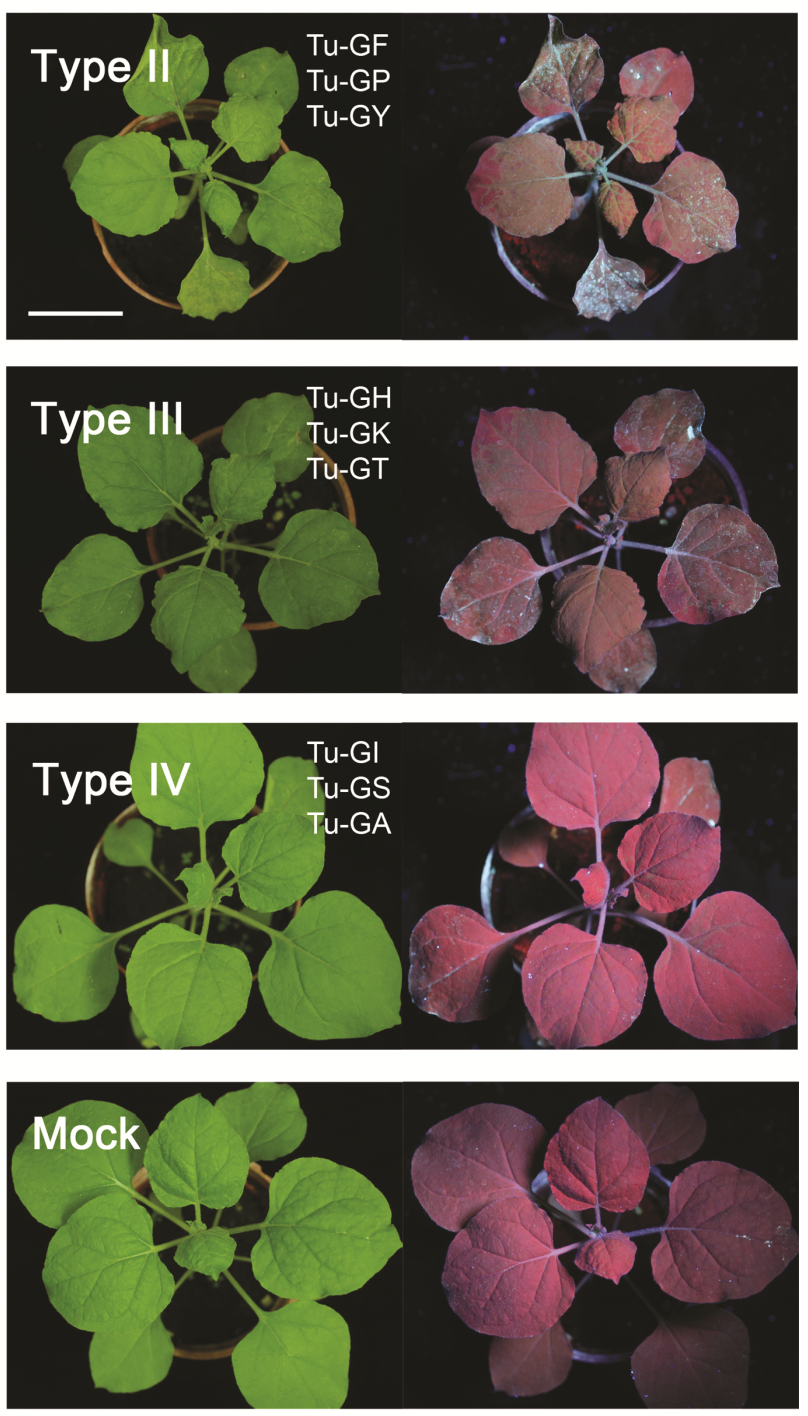

D

Type I vs. Type II

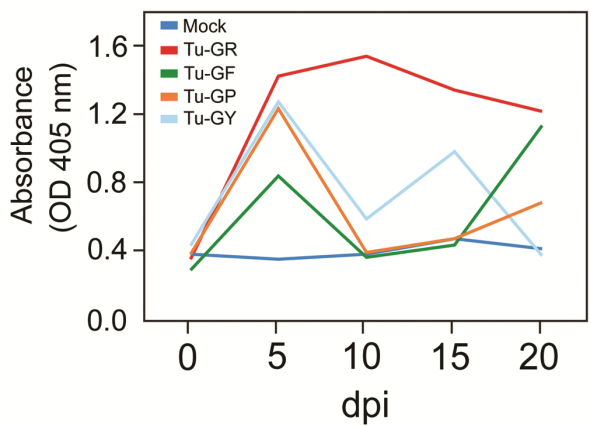

Type I vs. Type III

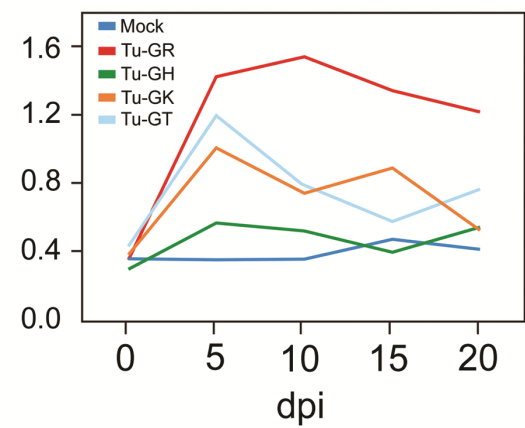

Type I vs. Type IV

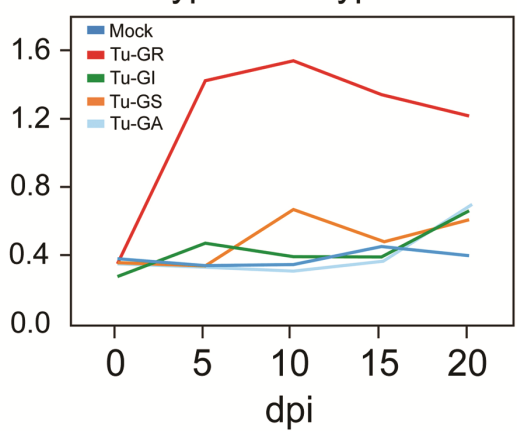

Fig. 1. Construction of Turnip mosaic virus (TuMV) mild strain. A, The upper schematic represents the conserved Arg position in the helper component-proteinase (HC-Pro) of Zucchini yellow mosaic virus (ZYMV) and TuMV. Another conserved position, E396, is indicated in the HC-Pro of ZYMV to explain the mild strain (GAC) mutation position. The lower schematic represents the wild-type TuMV HC-Pro protein (Tu-GR) and the Arg182 mutants in the TuGX series for the selection of the TuMV mild strains. The 19 single-substitution mutations at position 182 in HC-Pro and the corresponding names of the mutant viruses are indicated to the left of the diagram. Tu-GR contains the green fluorescent protein (GFP) expression cassette. R refers to Arg at position 182. In the mutant viruses, the X refers to the substituted amino acid at position 182. The "+" and "-" symbols indicate the presence and absence, respectively, of viral infection in Nicotiana benthamiana plants. Types of viral symptoms in the infected $N$. benthamiana plants for each mutant virus are indicated to the right side of the mutants. B, Type I symptoms were caused by Tu-GR in $N$. benthamiana plants. Photographs were taken at 14 days postinoculation (dpi) under white light (left panel) and UV light (right panel). C, Symptoms that developed in N. benthamiana plants were classified into type II, type III, and type IV. A representative plant from each category and the names of the mutants are shown. "Mock" indicates buffer-inoculated control. Photographs were taken at $14 \mathrm{dpi}$ under white light (left panels) and UV light (right panels). Bar $=2 \mathrm{~cm}$. D, Time courses of Tu-GR and Tu-GX virus titers in the infected $N$. benthamiana plants. Each absorbance value represents the average reading from three plants. The virus titer was determined using an antiserum against TuMV CP (Lin et al. 2013) at a 1/20,000 dilution. 
Tu-GK caused mild symptoms and retained partial silencing suppression function in Arabidopsis.

To establish the utility of Tu-GK for cross-protection studies in Arabidopsis, we first analyzed its infectivity, in comparison with Tu-GR as a control, in wild-type Arabidopsis Col-0 and mutant $d c l 2 / 4$ plants. This mutant line was chosen because DCL2 and DCL4 are primarily responsible for dicing viral RNAs to generate vsiRNAs to initiate anti-viral silencing (Bouché et al. 2006). The $d c l 2 / 4$ plants flowered earlier than Col-0 (Fig. 2A). Tu-GR caused curling inflorescence, stunted growth, and yellowing mosaic leaf in both Col-0 and $d c l 2 / 4$ plants (Fig. 2A and B). In contrast, Tu-GK-infected Col-0 plants were symptomless, phenotypically similar to mock- inoculated Col-0 plants (Fig. 2A and B). Tu-GK induced slight yellowing, leaf distortion, and shortened inflorescence symptoms in the $d c l 2 / 4$ plants, which were less severe than Tu-GRinfected $d c l 2 / 4$ plants (Fig. 2A and B).

The accumulation levels of Tu-GR and Tu-GK viral RNAs at different time points of infection in the Col-0 and $d c l 2 / 4$ plants were measured by real-time reverse-transcription polymerase chain reaction (RT-PCR) using GFP-coat protein $(C P)$-specific primers (Fig. 2C). The relative viral RNA levels at 5 and 10 dpi were compared with the RNA level at 0 dpi. Pairwise $t$ tests were used to determine if there were significant differences among samples at 5 and $10 \mathrm{dpi}$, respectively (Fig. 2C). At 5 dpi, the expression level of Tu-GK in Arabi-

\section{A}
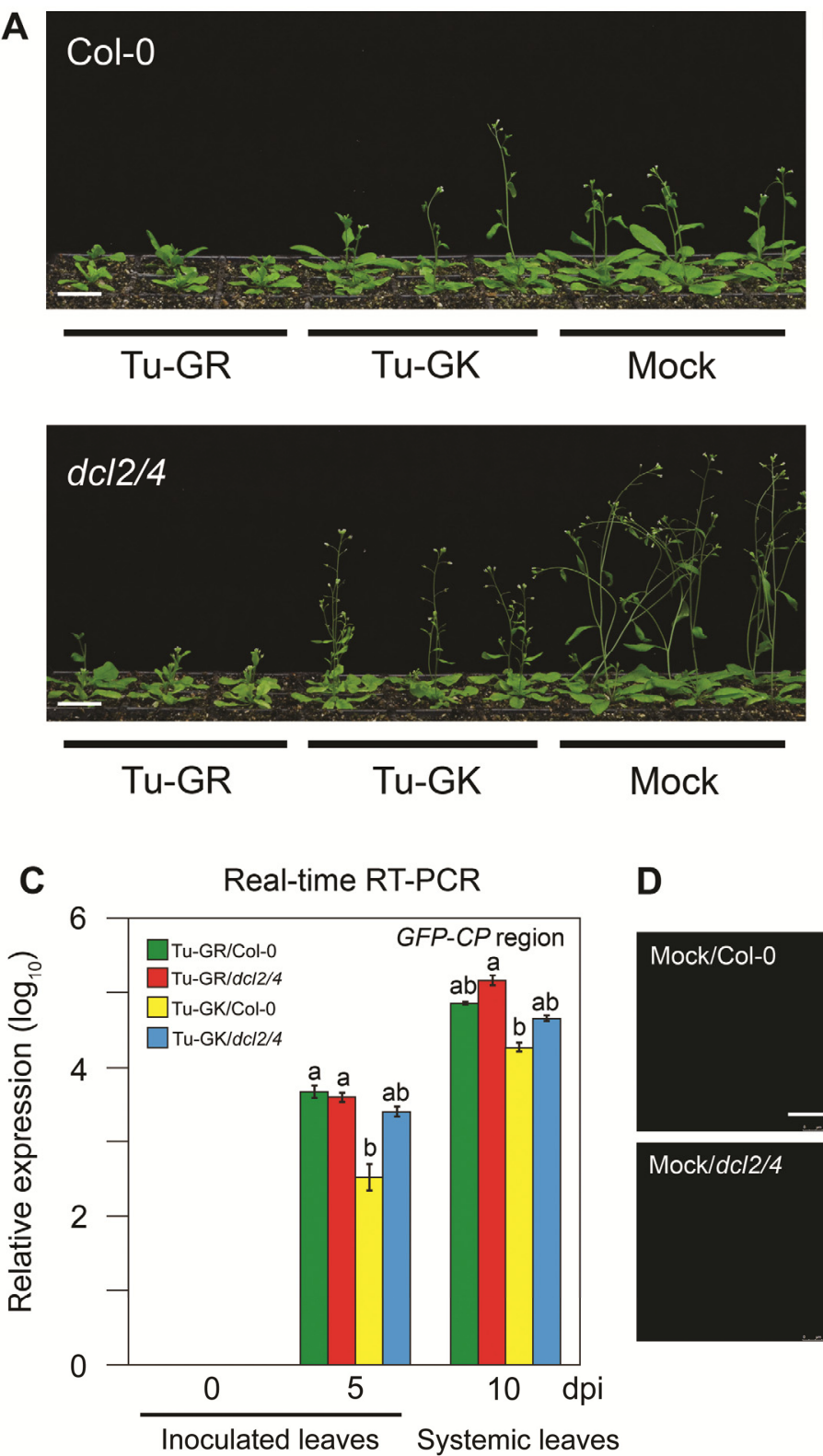

D

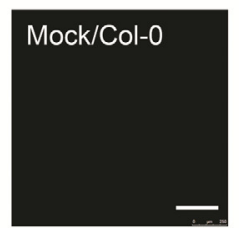

Mock/dc/2/4

B
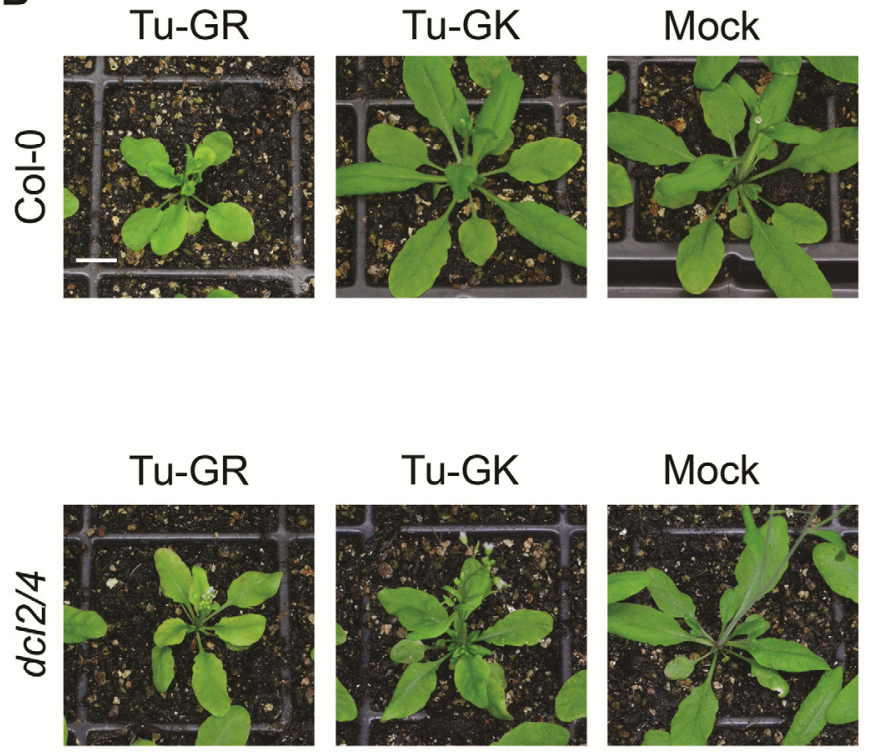

\section{Tu-GK}

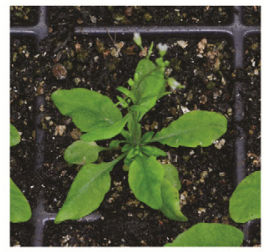

Mock

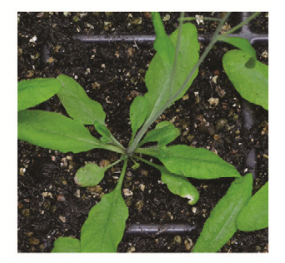

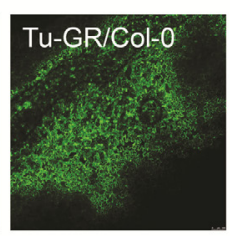

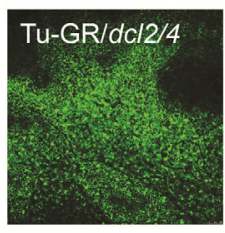

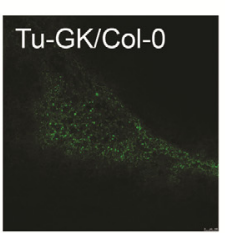

Tu-GK/dc/2/4
E

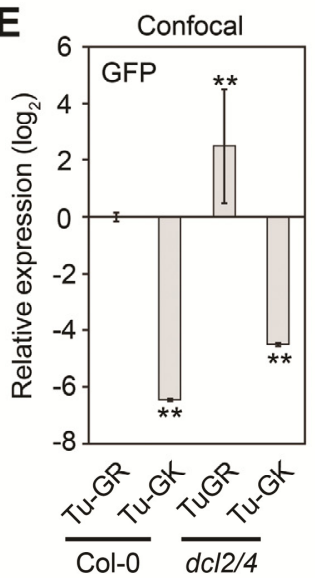

Fig. 2. Infectivity of Tu-GK in the Arabidopsis Col-0 and $d c l 2 / 4$ plants. A, Inflorescence symptoms in the Col-0 (upper panel) and the $d c l 2 / 4$ (lower panel) Arabidopsis plants infected with Tu-GR or Tu-GK. Tu-GR was used as a positive control. Photographs were taken at 14 days postinoculation $(\mathrm{dpi})$. Bar $=2.5 \mathrm{~cm}$. B, Yellowing symptoms on the leaves of Col-0 and $d c l 2 / 4$ plants after inoculation with Tu-GR or Tu-GK. Photographs were taken at $14 \mathrm{dpi}$. Bar $=1 \mathrm{~cm}$. C, Time courses of Tu-GR and Tu-GK viral RNA levels in the infected Col-0 and $d c l 2 / 4$ plants as evaluated by real-time reverse-transcription polymerase chain reaction with green fluorescent protein coat protein $(G F P-C P)$-specific primers. The value at each time point represents the average relative viral RNA levels $\left(\log _{10}\right)$ from three plants. Relative viral RNA levels were compared with those of the 0-dpi plants. Bars represent standard deviations $(n=3)$. Letters represent significant differences between the groups by $t$ test. D, GFP expression levels of Tu-GR or Tu-GK in the infected Col- 0 or $d c l 2 / 4$ plants at 10 dpi were observed by confocal microscopy. Mock-inoculated Col- 0 and $d c l 2 / 4$ plants were used as negative controls. Bar $=300 \mu \mathrm{m}$. E, Relative average GFP expression $\left(\log _{2}\right)$ of Tu-GR- or TuGK-infected leaves compared with that of Tu-GR-infected Col-0 plants as determined by confocal microscopy $(n=3)$. Relative expressions levels were significantly different from those of the Tu-GR/Col-0 plants in each RNA sample, based on a Student $t$ test; ** indicates $P$ values $<0.01$. 
dopsis Col-0 was significantly lower than that of Tu-GR $(P<$ 0.05); Tu-GK in the Arabidopsis dcl2/4 mutant had a lower expression level than Tu-GR but the difference did not reach the $P<0.05$ significance level. A similar scenario was also observed at $10 \mathrm{dpi}$; Tu-GR had a higher expression level than Tu-GK in Arabidopsis Col-0, although the difference was not significant at the $P<0.05$ level.

The different accumulation levels of Tu-GK and Tu-GR in these plants revealed by real-time RT-PCR were confirmed by confocal microscopic observation (Fig. 2D) and quantification (Fig. 2E) of GFP fluorescence derived from the tagged viruses.

Altogether, our results indicated that Tu-GK has compromised but still functional activity in suppressing host anti-viral defense. The role of Tu-GK in cross-protection was directly tested by the following experiments.

\section{Tu-GK conferred complete cross-protection in both Col-0 and $d c l 2 / 4$ plants.}

The cross-protection function of the Tu-GK mutant was evaluated in the Col- 0 and $d c l 2 / 4$ plants. Arabidopsis plants were first inoculated with Tu-GK as the protective virus (Fig. 3A). At $7 \mathrm{dpi}$, the plants were inoculated with YC5 as the challenge virus. ELISA analyses with anti-TuMV CP antibodies showed a significant reduction in the accumulation level of viral $\mathrm{CP}$ in Tu-GK-protected plants (Fig. 3B). To distinguish between Tu-GK and YC5 viruses in the protected plants, specific primers for each virus were used to amplify the $G F P-C P$ region of Tu-GK and the $N I b-C P$ region of YC5 (Fig. $3 C$ ). The real-time RT-PCR results showed that YC5 was present abundantly in unprotected plants but barely detectable in the protected plants (Fig. 3D). Our data indicated that Tu-GK infection of Arabidopsis conferred complete cross-protection against YC5 infection in both Col-0 and $d c l 2 / 4$ plants, consistent with earlier observations in $N$. benthamiana. Therefore, Tu-GK is a suitable mild strain for cross-protection in different plants. To gain insights into the potential mechanisms of Tu-GK function in cross-protection, or to understand the functional features of a protective, mild virus in cross-protection for future design of such a virus, we conducted the following experiments to examine various aspects of Tu-GK function in comparison with the Tu-GR control.

\section{DCL2/4-dependent and -independent accumulation of vsiRNAs.}

DCL2 and DCL4 targeted the double-stranded (ds), replicative forms of viral RNAs to generate 22- and 21-nt vsiRNAs that guide sequence-specific viral RNA degradation (Bouché et al. 2006). To determine whether Tu-GK would affect vsiRNA accumulation in comparison with the control Tu-GR, we used deep sequencing to analyze the vsiRNA profiles in Col- 0 and $d c l 2 / 4$ plants infected by the two viral strains. In TuGR-infected Col-0 plants, the 21-nt sense and antisense vsiRNA reads were higher than those in the Tu-GR-infected $d c l 2 / 4$ plants (Fig. 4A). The scatter plot and the regression analysis of the vsiRNA positions also showed the read counts moving toward the Col-0 side (the red dashed line below the $45^{\circ}$ red solid line) (Fig. 4B, left panel). It is possible that redundant function of DCL1 (Bouché et al. 2006; Deleris et al. 2006) or other ribonucleases compensated for the defective $d c l 4$ function to generate the 21-nt vsiRNAs (Bouché et al. 2006). In contrast, there were no significant differences in the 21-nt vsiRNA reads in the Tu-GK-infected Col-0 and dcl2/4 plants (Fig. 4A). This was confirmed by scatter plots (Fig. 4B, right panel; the red dashed line was close to the $45^{\circ}$ red solid line). We suggest that the inefficient suppression of DCL2 and DCL 4 by $\mathrm{HC}^{-P r o}{ }^{\mathrm{K}}$ in the Col- 0 plants resulted in a low titer of Tu-GK RNA as substrate for vsiRNA production.

The 22-nt vsiRNA levels in Tu-GR-infected $d c l 2 / 4$ plants showed a twofold reduction compared with those of Tu-GRinfected Col-0 plants, likely as a result of loss of $d c l 2$ function (Fig. 4A). In addition, the 22-nt vsiRNA levels were considerably lower than the 21-nt vsiRNA levels in the Tu-GR-infected Col-0 plants, suggesting that DCL2 plays a less efficient role in TuMV resistance (Fig. 4A). In contrast to the 21- and 22-nt vsiRNAs, the 24-nt vsiRNA levels increased approximately 95-fold in the Tu-GR- or Tu-GK-infected $d c l 2 / 4$ plants com-
A

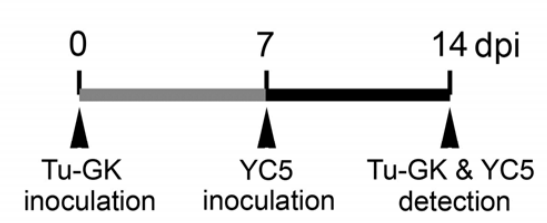

C

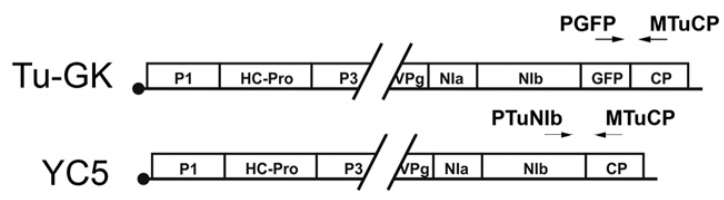

D

Real time RT-PCR

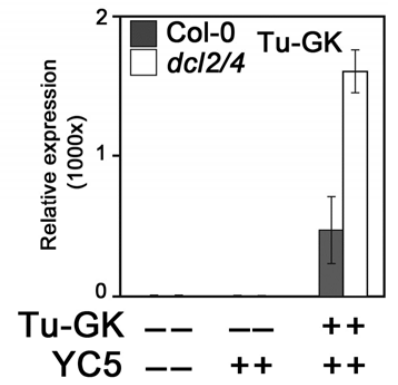

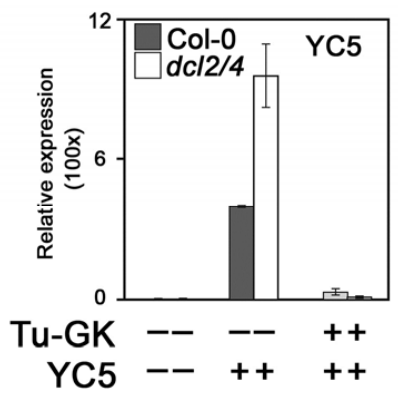

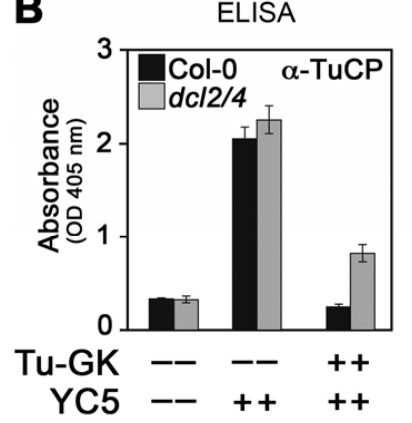

Fig. 3. Cross-protection in Arabidopsis Col-0 and dcl2/4 plants caused by infection with mild-strain viruses. A, The procedure for cross-protection (upper panel). Arrows indicate the time points of inoculation and detection for the protective virus (Tu-GK) and the challenge virus (YC5). B, Tu-GK confers crossprotection against the YC5 in the Col-0 (black column) and $d c l 2 / 4$ mutant (gray column) strains of Arabidopsis. The enzyme-linked immunosorbent assay (ELISA) analysis was performed at 14 day postchallenge using the TuMV coat protein (CP) antibody at a 1/20,000 dilution. Bars represent standard deviations $(n=3)$. C, The schematic represents the primer sets for the detection of Tu-GK or YC5 by real-time reverse-transcription polymerase chain reaction (RT-PCR). Arrowheads indicate the primer positions. D, Distinguishing between YC5 and Tu-GK from co-infected plants by real-time RT-PCR using specific primer sets. Relative expressions levels were normalized to the ubiquitin level. Bars represent standard deviations $(n=3)$. 
pared with those in the Col-0 plants (Fig. 4A). These data suggested that DCL3 compensatorily cleaves the viral dsRNAs in the absence of $d c l 2$ and $d c l 4$ functions (Bouché et al. 2006).

P1/HC-Pro ${ }^{\mathrm{K}}$ sustained a low level of sense-PTGS suppression activity.

The above viral infection experiments suggested that $\mathrm{Tu}-$ GK retained partial RNA silencing function. To test directly the suppression ability of $\mathrm{HC}-\mathrm{Pro}^{\mathrm{K}}$ on sense-PTGS, the P1/HC-Pro ${ }^{K}$ and $P 1 / H C-$ Pro $^{R}$ (control) genes were expressed under the control of the $35 S$ promoter in the $\beta$-glucuronidase $(G U S)$ sense-PTGS transgenic Arabidopsis L1 line, which normally shows low or no GUS expression (Fig. 4C, lower panel). Two independent lines having similar expression levels of HC-Pro for each construct were selected for further anal (Fig. 4D).
A

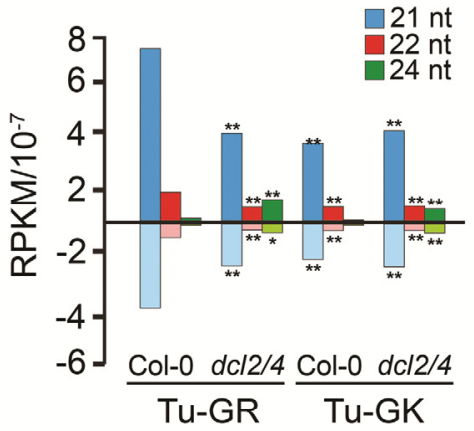

B 15

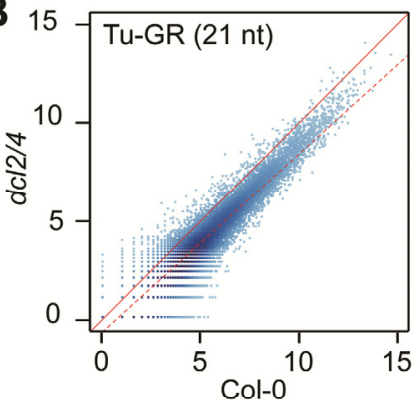

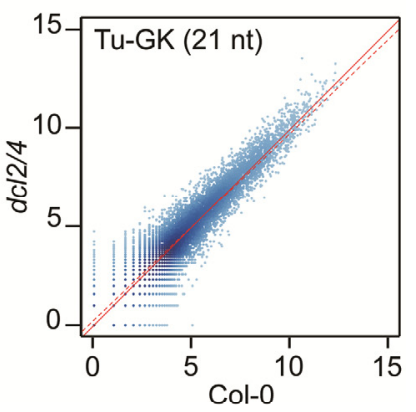

C
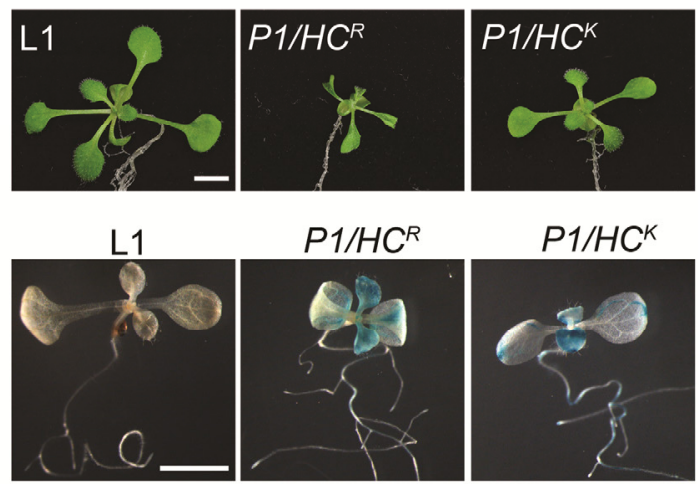

$P 1 / H C^{R}$
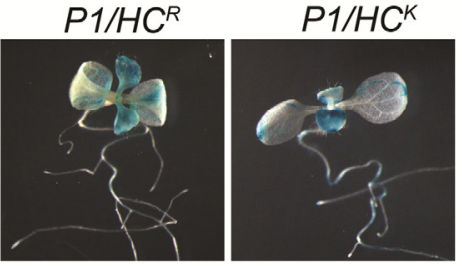

D

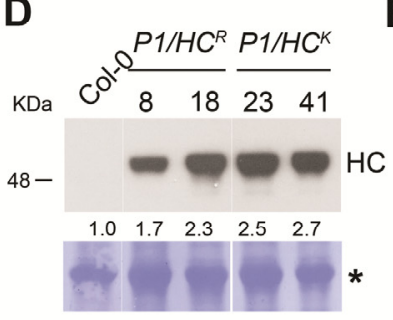

E

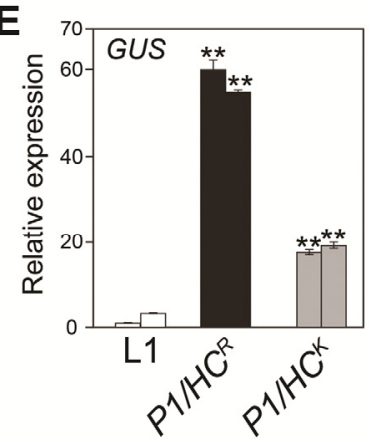

F

$P 1 / H C^{R} \quad P 1 / H C^{K}$

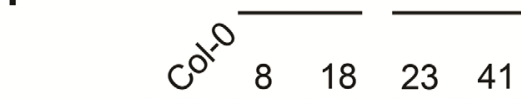

$\operatorname{miR} 165$

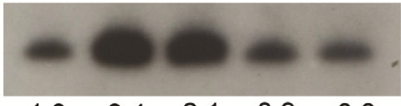

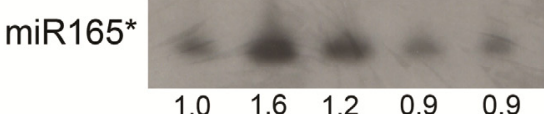

$\operatorname{miR} 168$

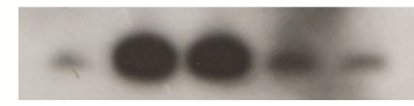

$\operatorname{miR} 168^{*}$
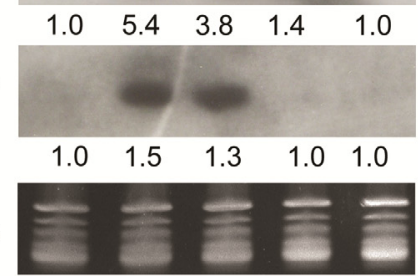

Fig. 4. Effects of TuMV wild-type $\mathrm{P} 1 / \mathrm{HC}-\mathrm{Pro}^{\mathrm{R}}$ and mutant $\left(\mathrm{P} 1 / \mathrm{HC}-\mathrm{Pro}^{\mathrm{K}}\right)$ on the morphological and molecular phenotypes of transgenic Arabidopsis plants. A, Accumulation of virus-derived siRNAs of Tu-GR and Tu-GK in the Col-0 and $d c l 2 / 4$ plants. The different sizes of the sense and antisense of TuMVderived short-interfering (si)RNAs accumulated in the Col- 0 and $d c l 2 / 4$ plants. The dark blue (21 nucleotides [nt]), red ( $22 \mathrm{nt})$, and green ( $24 \mathrm{nt})$ boxes indicate the sense-strand siRNAs, whereas the light blue (21 nt), pink ( $22 \mathrm{nt})$, and light green ( $24 \mathrm{nt})$ boxes indicate the antisense-strand siRNAs. The scale of the reads per kilobase of exon model per million mapped reads (RPKM) was divided by $10^{7}$. The read counts were significantly different from those of the Col-0 plants in each small RNA sample based on the Poisson test; ** indicates $P$ values $<10^{-100}$. B, Scatter plots of the read counts of the $d c l 2 / 4$ plants against the read counts of the Col-0 plants. The $\mathrm{x}$ - and y-axes are indicated in the $\log _{2}$ read counts. The red solid line is the $45^{\circ}$ straight line; the red dashed line is based on the results of a simple regression using the read counts of the Col-0 plants as the predictor variables and the read counts of the $d c l 2 / 4$ plants as the response variables. C, Representative phenotypes of transgenic Arabidopsis plants expressing $P 1 / H C$-Pro ${ }^{R}$ and $P 1 / H C$-Pro ${ }^{K}$ genes in the L1 line background. Photographs were taken using 2 -week-old seedlings. The L1 line is a post-transcriptional gene silencing transgenic Arabidopsis expressing the $\beta$-glucuroni-

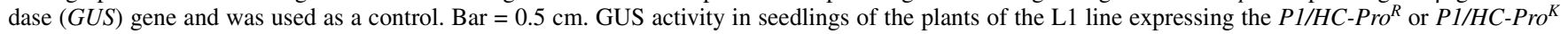
genes. Bar $=0.5 \mathrm{~cm}$. D, HC-Pro expression levels in transgenic Arabidopsis lines. At least two independent lines for each construct were analyzed. The numbers on the panel represent the signal strengths of the HC-Pro levels after normalization against ribulose-1,5-bisphosphate carboxylase (*) using the large subunit levels as loading controls. A polyclonal antibody against HC-Pro was used at a 1/10,000 dilution for Western blot detection. E, Evaluation of the $\mathrm{P} 1 / \mathrm{HC}-\mathrm{Pro}{ }^{\mathrm{R}}$ and P1/HC-Pro ${ }^{\mathrm{K}}$ suppression efficiency in GUS expression in the L1 line background by real-time reverse-transcription polymerase chain reaction. Relative expression levels were normalized with the ubiquitin level. Bars represent standard deviations $(n=3)$. F, Effects of P1/HC-Pro ${ }^{\mathrm{R}}$ and P1/HCPro $^{\mathrm{K}}$ on microRNA (miRNA) and miRNA* accumulation. Oligonucleotides complementary to miRNA and miRNA* were used as probes. 5S ribosomal RNA (rRNA) and transfer RNA (tRNA) were used as loading controls. Numbers on the panels represent the average signal strengths of the miRNAs relative to those in the non-transformed wild-type plants (Col-0) after normalization against the loading control. Levels in the Col-0 plants were set at 1.0 . Two independent lines for each construct were analyzed. 
Both $P 1 / H C^{R}$ and $P 1 / H C^{K}$ plants stained positively for GUS, with indistinguishable levels (Fig. 4C). However, quantification of GUS mRNA levels with real-time RT-PCR revealed a significant difference between plants expressing the two Pl/ $H C$-Pro constructs. Although $P 1 / H C^{R}$ plants showed approximately 59-fold increase in GUS mRNA level compared with that of the L1 line, $P 1 / H C^{K}$ plants showed a 19-fold increase (Fig. 4E). Thus, $P 1 / H C^{K}$ retained the function of suppressing sense-PTGS but at a significantly lower level than $P 1 / H C^{R}$. This was consistent with the results from the above viral infection analyses.

\section{P1/HC-Pro ${ }^{\mathrm{K}}$ did not cause abnormal phenotypes} or interfere with miRNA pathways in Arabidopsis.

The $P 1 / H C^{R}$ plants showed a severe serrated leaf phenotype that is typical of a defective miRNA pathway, as reported earlier (Kasschau et al. 2003; Lin et al. 2007b). However, the $P 1 / H C^{K}$ plants did not exhibit any abnormal phenotypes (Fig. 4C). This
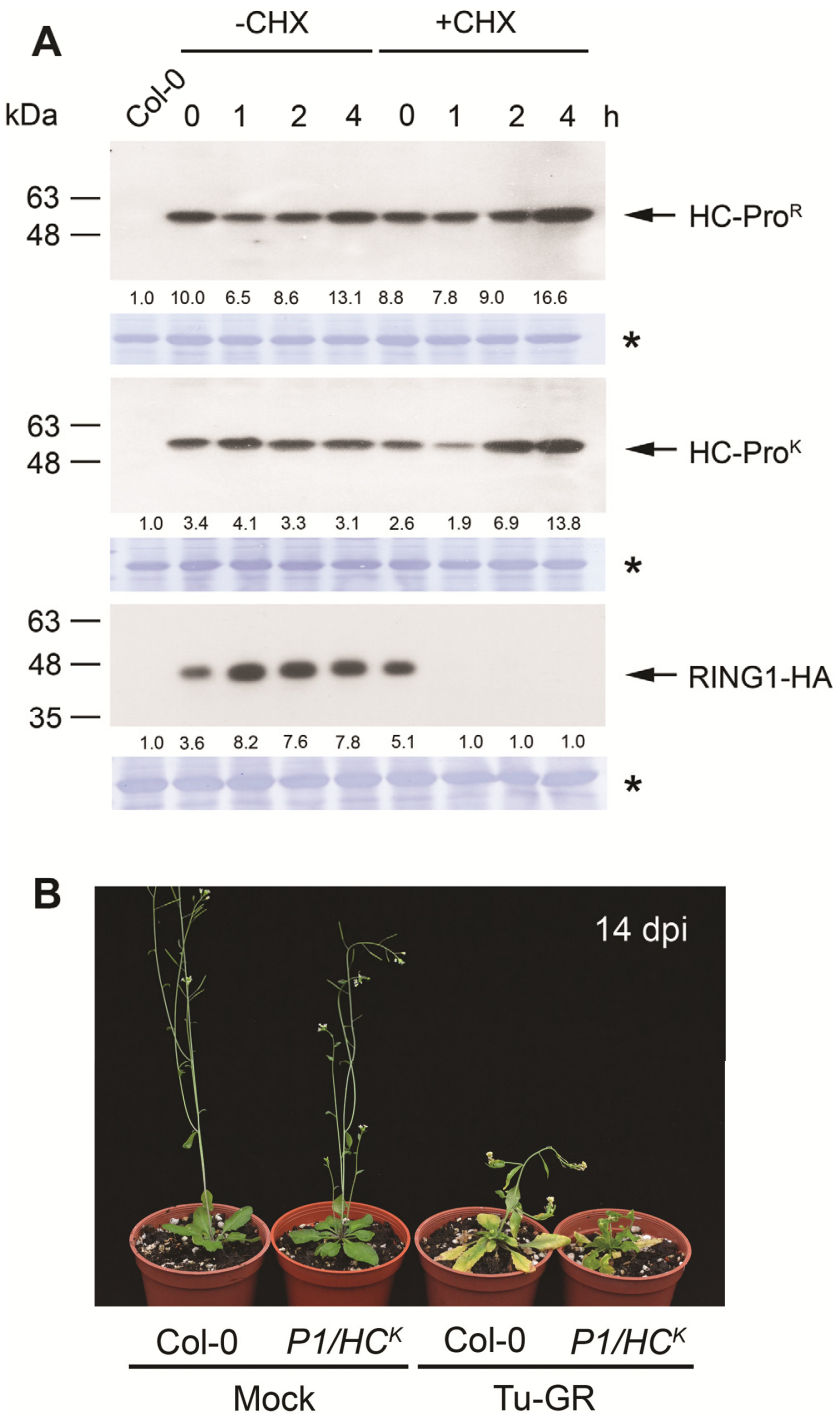

Fig. 5. Evaluation of $\mathrm{HC}-\mathrm{Pro}^{\mathrm{K}}$ protein-mediated resistance. A, Stability of HC-Pro ${ }^{\mathrm{R}}$ and HC-Pro ${ }^{\mathrm{K}}$ in vivo. Two-week-old Arabidopsis seedlings overexpressing P1/HC-Pro ${ }^{\mathrm{R}}$ and $\mathrm{P} 1 / \mathrm{HC}-\mathrm{Pro}^{\mathrm{K}}$ were used. Samples were treated with or without $200 \mu \mathrm{M}$ cyclohexamide (CHX). HC-Pro protein levels were analyzed after various treatment durations. Migration positions of protein markers $(\mathrm{kDa})$ are indicated on the left. The ubiquitin E3 ligase RING1-HA was used as a positive control. B, Examination of protein-mediated resistance in $P 1 / H C^{K}$ plant by challenge with Tu-GR. Photographs were taken at 14 days postinoculation (dpi). suggested that $P 1 / H C^{K}$, while still retaining partial silencingsuppression function, might not negatively affect miRNA metabolism. To test this directly, we analyzed several miRNAs that have altered expression levels in correlation with the altered plant phenotype in transgenic Arabidopsis expressing the TuMV HC-Pro (Kasschau et al. 2003). Our results showed that miR165/miR165* and miR168/miR168* exhibited increased accumulations in the $P 1 / H C^{R}$ plants compared with that in the Col-0 plant (Fig. 4F), as previously reported (Kasschau et al. 2003). In contrast, the $P 1 / H C^{K}$ plants had expression levels of these miRNAs similar to the Col-0 plants (Fig. 4F). Therefore, P1/HC-Pro ${ }^{\mathrm{K}}$ retained partial sense-PTGS suppression but did not appear to interfere with the general miRNA pathways.

\section{HC-Pro ${ }^{\mathrm{K}}$ had stability similar}

to the wild-type $\mathrm{HC}$-Pro ${ }^{\mathrm{R}}$ in planta.

The partial loss of suppression activity of $P 1 / H C^{K}$ could be attributed to faster turnover of the protein caused by the mutation or to other factors. To address this, we next analyzed the

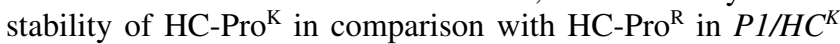
and $P 1 / H C^{R}$ plants treated with $200 \mu \mathrm{M}$ cyclohexamide $(\mathrm{CHX})$. Both $\mathrm{HC}^{-} \mathrm{Pro}^{\mathrm{R}}$ and $\mathrm{HC}-\mathrm{Pro}^{\mathrm{K}}$ exhibited similar stability during the 4-h period of CHX treatment (Fig. 4A). As a control, RING1, an E3 ubiquitin ligase with a rapid turnover rate (Lin et al. 2008), was degraded $1 \mathrm{~h}$ after CHX treatment (Fig. 5A). Thus, the partial loss of suppression activity of $P 1 / H C^{K}$ was due to factors other than protein stability.

We further investigated whether $\mathrm{P} 1 / \mathrm{HC}^{\mathrm{K}}$ would have a dominant negative effect in protein-mediated resistance. We challenged the $P 1 / H C^{K}$-transgenic plants with Tu-GR virus. At $14 \mathrm{dpi}$, the plants showed severe symptoms (Fig. 5B). Thus, $\mathrm{HC}^{-} \mathrm{Pro}^{\mathrm{K}}$ did not provide protein-mediated resistance to Tu-GR infection.

\section{Evidence for crosstalks \\ between RNA silencing and plant innate immunity.}

In addition to RNA silencing-based adaptive immunity, various innate immunity mechanisms have also evolved in plants. To test whether RNA silencing would crosstalk with plant innate immunity pathways, we analyzed the expression of several genes that play critical roles in innate immunity in Col-0 and $d c l 2 / 4$ plants infected by Tu-GR and Tu-GK, respectively. At 10 dpi, Tu-GK had lower viral titers than Tu-GR in Col-0 and $d c l 2 / 4$ plant (Fig. 6A). First, we analyzed the expression of the SA-dependent defense marker gene PATHOGENESISRELATED GENE 1 (PRI). Col-0 and dcl2/4 plants infected by Tu-GR or Tu-GK all showed elevated expression of PRI (approximately 42- to 64-fold increase compared with expression in the mock-inoculated plants) (Fig. 6B).

Next, we measured the expression of defense genes involved in SA biosynthesis (SID2 and EDS5) (Fig. 6C), SA accumulation and signaling (WIN3, FMO1, and PAD4) (Fig. 6D), and SA downstream signaling (WRKY51) (Fig. 6E) pathways (Ho et al. 2013; Mishina and Zeier 2006; Nawrath et al. 2002; Wang et al. 2011a; Wildermuth et al. 2001; Zhou et al. 1998). We also measured the expression of SA-independent defense genes $A I G 1$ and DOX1 (Fig. 6F). These measurements revealed two major patterns. First, their expression levels were generally lower in $d c l 2 / 4$ plants than in Col-0 plants infected by both TuMV strains. This indicates that expression of DCL2/4 is necessary for the proper expression of these genes under viral infection conditions. Second, the expression levels of these genes were generally higher in both types of plants infected by Tu-GK than those infected by Tu-GR. Thus, dampened silencing suppressor activities, and perhaps also low viral titers, appear to trigger stronger innate immune responses. Taken together, the requirement for the RNA silencing machinery for 
the proper expression and the downregulated expression by a full-functional viral silencing suppressor of these defense genes suggests crosstalks between adaptive immunity based on RNA silencing and innate immunity based on other mechanism. How these two immunity pathways interact for general plant defense for cross-protection is an outstanding question for future investigations.

\section{DISCUSSION}

Knowledge of the mechanisms of cross-protection has significant implications in understanding the evolution and pathogenesis of viruses and in developing practical methods to control viral diseases. Using mutagenesis, we generated Tu-GK as a mild strain of TuMV that provided complete cross-protection in N. benthamiana and Arabidopsis plants. Characterization of this strain allowed us to define several important criteria for a useful protective virus that may help future development of new protective strains for other viruses. Furthermore, studies of this strain shed new light on the potential interplay between RNA silencing and innate immunity pathways in cross-protec- tion, which may enable further in-depth studies to better understand plant defense mechanisms.

\section{Criteria for a suitable mild strain for cross-protection.}

Based on the findings from this study and from the literature, we proposed four criteria for the identification of a useful mild strain for effective cross-protection. First, a mild strain should have an inefficient suppressor that does not interfere with miRNA pathways and does not induce severe symptoms in protected plants, as exemplified by P1/HC-Pro ${ }^{\mathrm{K}}$ characterized in this study. As further support of this criterion, the $2 b$ deletion mutant of CMV (Fny-CMV $\Delta 2 b$ ) also caused no symptoms and conferred cross-protection against the Fny-CMV severe strain in Col-0 plant (Ziebell and Carr 2009).

Second, for survival and maintenance of replication, the silencing suppressor of a mild strain should retain partial suppression of the DCL2/DCL4-mediated viral defense. P1/HCPro $^{\mathrm{K}}$ retains $33 \%$ of the wild-type efficiency in sense-PTGS suppression, enabling the virus to sustain a moderate titer in the Tu-GK-protected Col-0 plants (Fig. 2C). Similar results

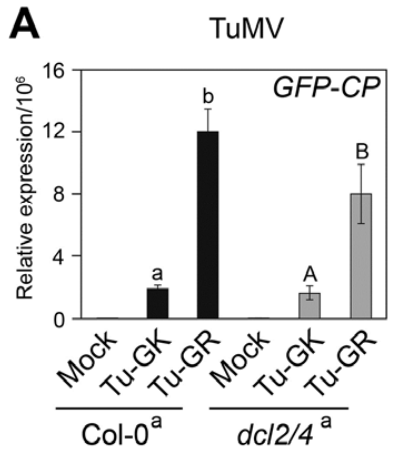

B

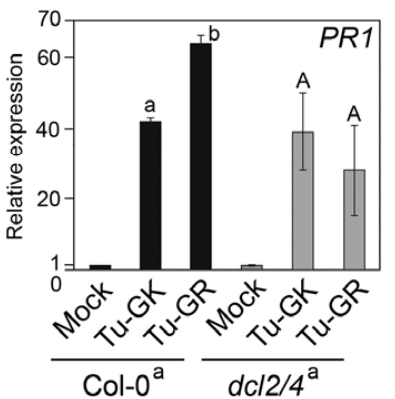

SA accumulation and signaling
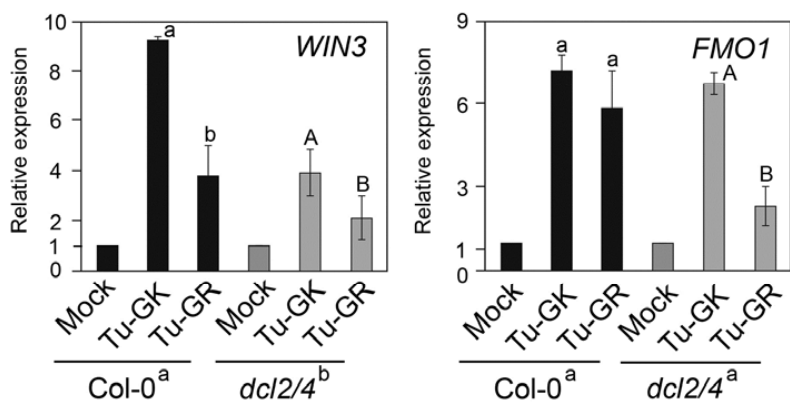

C
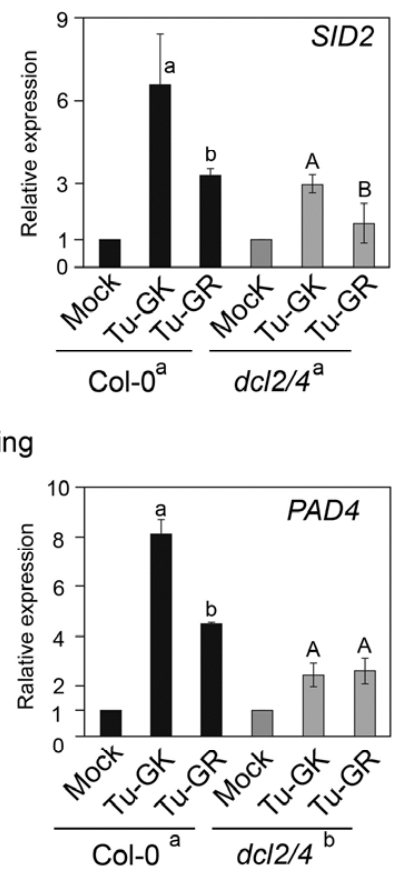

SA biosynthesis

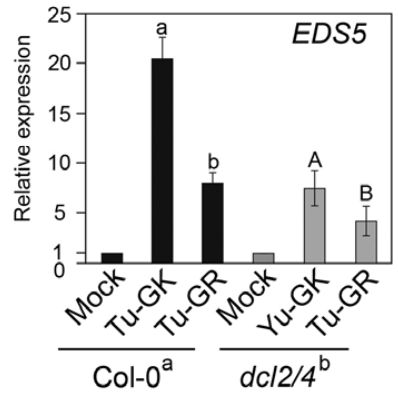

E SA downstream signaling

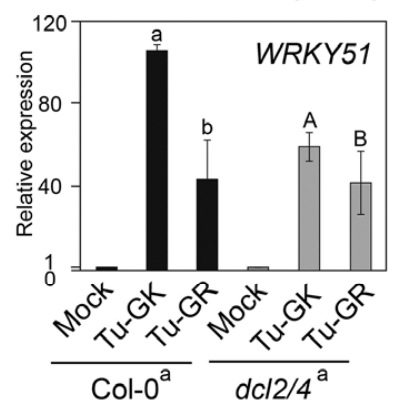

$\mathbf{F}$
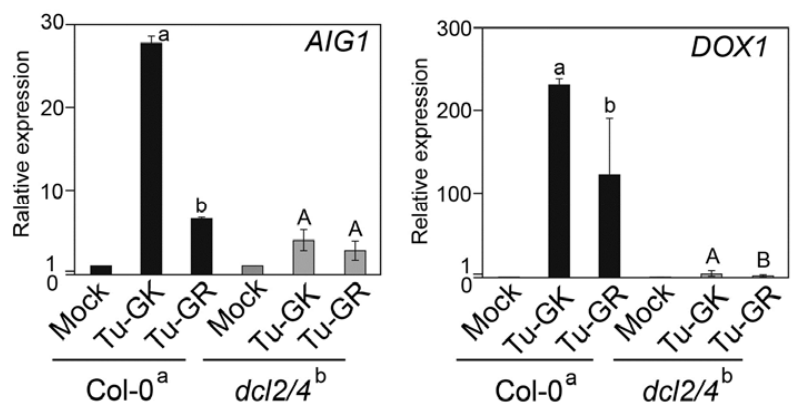

Fig. 6. Differential expression of defense genes assessed by real-time reverse-transcription polymerase chain reaction in Tu-GK- or Tu-GR-infected Arabidopsis Col-0 and dcl2/4 plants. A, Detection of TuMV accumulation at 10 days postinoculation by monitoring the green fluorescent protein coat protein $(G F P-C P)$ region. B, Expression of defense marker gene (PR1). C, Expression of salicylic acid (SA) biosynthesis genes (SID2 and EDS5). D, Expression of WIN3, FMO1, and PAD4, which are regulated in SA accumulation and signaling pathways. E, Expression of WRKY51, which is involved in SA downstream signaling. F, Expression of $A I G 1$ and $D O X 1$, which are involved in other plant defense response-associated pathways. Bars represent standard deviations $(n=3)$. Letters represent significant differences between the Tu-GK/Tu-GR and Col-0/dcl2/4 using the $t$ test. 
were obtained with infection of Fny-CMV $\Delta 2 \mathrm{~b}$ in $d c l 2 / 3 / 4$ or $d c l 2 / 4$ plants (Ziebell and Carr 2009).

Third, a moderate and sustained titer of a protective virus is necessary to trigger cross-protection. The type IV TuMV mutants have low titers in infected plants that cannot trigger crossprotection (data not shown). This is consistent with findings from a protection examination of ZYMV GAB (ZGAB) that has a titer too low to trigger cross-protection in zucchini squash (Lin et al. 2007b). In contrast, Tu-GK has a moderate titer that can sustain viral survival in the host to trigger cross-protection. This was also shown in GAC-mediated incomplete protection in zucchini squash before $5 \mathrm{dpi}$, in which the inhibition of challenge virus replication by GAC depends on the titer (Lin et al. 2007b). In addition, our data suggest that the moderate titer of Tu-GK triggers strong innate immune responses against infection by a challenge virus. As further support of this notion, P1 of the genus Potyvirus interferes SA-dependent defense pathway, and low titers of a mutant Plum pox virus with the N-terminal P1 deleted are correlated with higher expression levels of SA-associated genes in infected plants (Pasin et al. 2014).

Finally, the mild strain should produce stable mild symptoms and yet should not cause severe adverse effects on the protected host. Tu-GK showed stable mild symptoms in $N$. benthamiana and was symptomless in Arabidopsis for more than four passages (data not shown). The same phenomenon was observed for ZYMV mild strains in zucchini squash (GalOn 2000; Lin et al. 2007b).

\section{DCL2/DCL4-dependent and -independent vsiRNA generation.}

DCL2 and DCL4 are major RNase III proteins involved in the biogenesis of 22- and 21-nt vsiRNAs, respectively (Bouché et al. 2006; Deleris et al. 2006; Moissiard et al. 2007). Our data showed that the majority of vsiRNAs derived from TuMV were $21 \mathrm{nt}$, and that the 21-nt vsiRNAs were reduced in the $d c l 2 / 4$ plants, indicating that DCL4 plays a more critical role in vsiRNA biogenesis (Fig. 4A). This is consistent with the findings of Garcia-Ruiz and associates (2010). These types of vsiRNAs (22 and $21 \mathrm{nt}$ ) were classified as DCL2/DCL4-dependent vsiRNAs (Bouché et al. 2006). In addition, 24-nt vsiRNAs increased in the infected $d c l 2 / 4$ plants, likely as a result of DCL3 function in the $d c l 2$ and $d c l 4$ double mutant (Bouché et al. 2006).

Of particular significance is that a large pool of 21-nt vsiRNAs was detected in the infected $d c l 2 / 4$ plants. Because $d c l 2 / 4$ is a null mutant (Bouché et al. 2006), these 21-nt vsiRNAs are obviously produced by an alternate pathway via the use of other types of ribonucleases from the host. Bouché and associates (2006) suggested that another RNase III in the dcll/dcl2/dcl3/dcl4 quadruple mutant could produce vsiRNAs. Therefore, we postulate that DCL2/DCL4-independent vsiRNAs might exert the resistance observed in the Tu-GK-protected $d c l 2 / 4$ plants. Uncovering such vsiRNA biogenesis mechanisms and demonstrating loading of such vsiRNAs into AGO proteins for consistent PTGS function are outstanding challenges for future studies.

\section{The crosstalk between PTGS and innate immunity.}

Recent studies suggest that the PTGS machinery crosstalks with various gene regulatory pathways, such as autophagy and alternative splicing (Derrien et al. 2012; Gibbings et al. 2012; Morlando et al. 2008). Several lines of evidence also suggest that SA-dependent defense pathways crosstalk with PTGS (Garcia-Ruiz et al. 2010; Rakhshandehroo et al. 2009; Yang et al. 2004) and that DCL2 and DCL4 are involved in SA-dependent and -independent defense pathways. Recently, Pasin and associates (2014) demonstrated that P1 has modulates SAdependent pathway. These findings implicate crosstalk between the PTGS machinery and innate immunity as a new direction of research in the future.

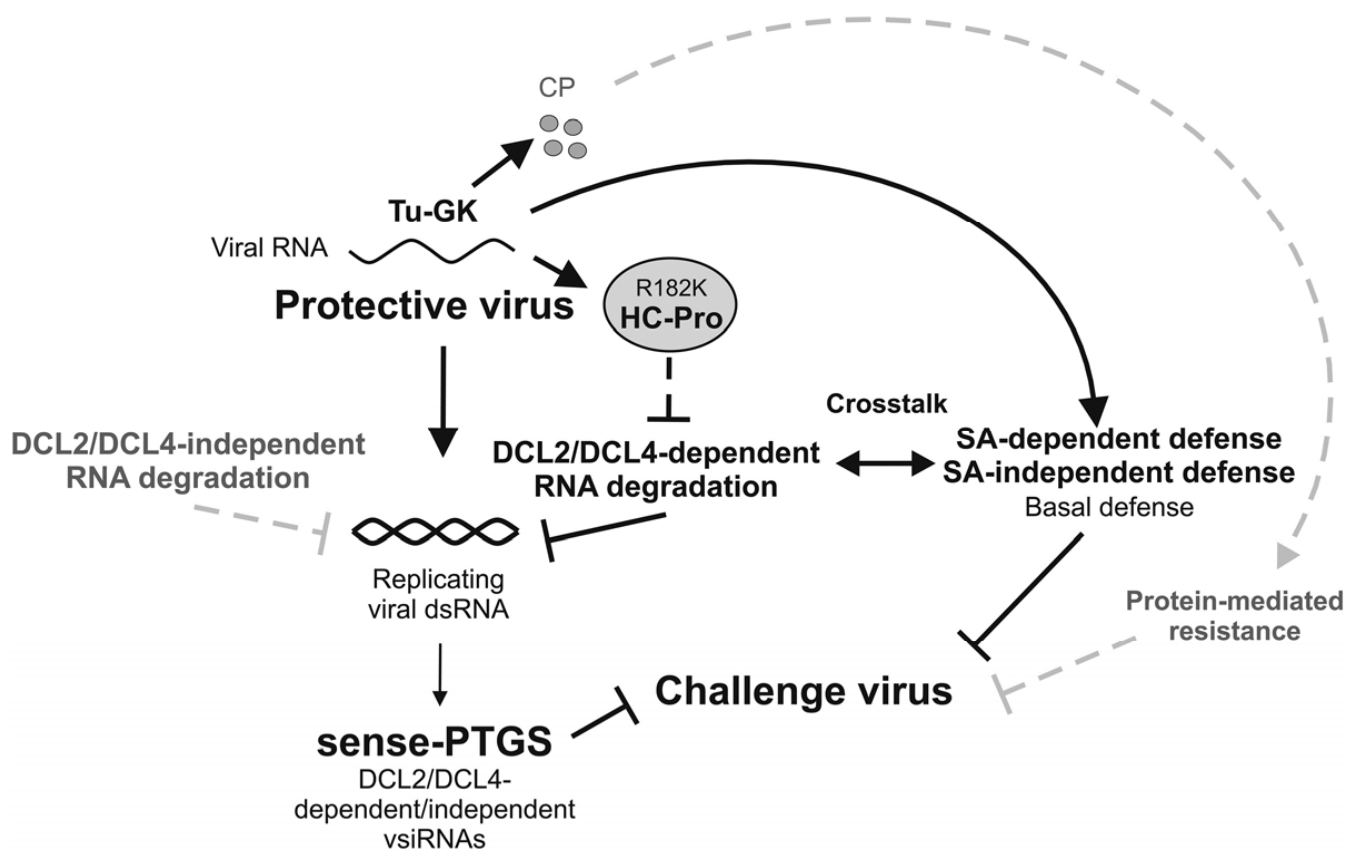

Fig. 7. Proposed model of Tu-GK-induced cross-protection. The replicating Tu-GK produces double-stranded viral RNAs (dsRNAs) that serve as a pathogen-associated molecular pattern. The DCL2 and DCL4 recognize the dsRNAs, triggering RNA-mediated silencing (DCL2/DCL4-depedent and -independent RNA degradation). The HC-Pro ${ }^{\mathrm{K}}$ in Tu-GK is compromised in suppression of DCL-mediated post-transcriptional gene silencing (PTGS), resulting in low titers of the Tu-GK virus in the host cells that are sufficient to maintain RNA silencing. Tu-GK infection triggers strong salicylic acid (SA)-dependent and SA-independent innate immunity responses. In addition, Tu-GK may provide protein-mediated resistance, including competition for viral proteins and sequestration of essential host factors to suppress the replication of the challenge virus. DCL2/4-dependent RNA silencing pathways may crosstalk with basal innate immunity pathways in host defense and in cross-protection. The dotted line represents defective suppression of PTGS by HC-Pro ${ }^{\mathrm{K}}$. Gray lines and arrowheads indicate the suggested pathways or mechanisms for cross-protection. 
A working model for cross-protection.

In Figure 7, we propose a working model for Tu-GK-induced cross-protection. In early infection of Tu-GK, no RNA-silencing is induced. However, the dsRNAs of Tu-GK produced during replication are recognized by DCL2/DCL4 or other RNase III proteins to trigger DCL2/DCL4-dependent and -independent gene silencing. This RNA-mediated silencing targets the genomic RNA of the challenge virus for degradation. During TuGR-mediated ETI, HC-Pro ${ }^{\mathrm{R}}$ suppresses DCL2/DCL4-dependent gene silencing, resulting in susceptibility to infection. However, HC-Pro ${ }^{\mathrm{K}}$ of the Tu-GK mutant is incapable of fully suppressing the DCL2/DCL4-mediated pathway in the host, thus resulting in a moderate titer of Tu-GK. The moderate virus titer and the inability to interfere with miRNA biogenesis result in symptomless infection in Tu-GK-infected Col-0 plants. Because Tu-GK continues to exist in the host, protein-mediated resistance for sequestering the essential host or virus factors might play a role to suppress the challenge virus infection through the CP of Tu-GK or through sequestration of essential host factors by Tu-GK. In addition, the Tu-GK infection also triggers SA-dependent and independent defense pathways to provide a basal defense response to the challenge virus. However, the basal innate immunity alone may not be responsible for conferring complete crossprotection because this response has no specificity. Finally, we found that DCL2 and DCL4 can crosstalk with innate immunity, defining a new direction for further study on virus-induced secondary signaling for acquired resistance. Further studies will determine the extent to which innate immunity pathways participate in or interact with RNA silencing in cross-protection. In summary, our working model suggests multiple and likely interactive mechanisms of resistance in viral cross-protection.

\section{MATERIALS AND METHODS}

\section{Plant materials and growth conditions.}

A. thaliana and $N$. benthamiana plants were sown directly on Florabella potting compost/sand mix (3:1) and maintained in a growth room (16 h of light and $8 \mathrm{~h}$ of darkness at 20 to $25^{\circ} \mathrm{C}$ ). The Arabidopsis dcl2/4 double mutant, derived from $d c l 2-4$ (FLAG_451B03) $\times$ dcl4-1 (FLAG_330A04), was provided by $\mathrm{H}$. Vaucheret (Bouché et al. 2006).

\section{Infectious clones and virus inocula.}

The Taiwan strain of the TuMV infectious clone (p35STuMV-GFP) includes a 35S promoter, GFP gene, and the full-length cDNA of the TuMV YC5 strain (Chen et al. 2003). The GFP gene was inserted between the $N I b$ and the $C P$ genes to generate chimeric Tu-GR (Lin et al. 2009; Niu et al. 2006). Tu-GR was used as a surrogate wild-type virus and a backbone for the construction of various recombinant viruses described herein. PCR-mediated mutagenesis was used to generate serial single mutations individually, to substitute Arg182 in HC-Pro, and to introduce a restriction enzyme site for screening the clones. For example, to generate Arg182Lys mutation, the primer sets PTuHCSphI-F (5'-CAAGCATGCAGTGCAGA TAC-3')/MTuHCBamHI-A (5'-CTTGTTAAGAAAGGACTT CAAGGATCCC-3') and PTuHCBamHI-A (5'-GGGATCCTT GAAGTCCTTTCTTAACAAG-3')/MTuHCSphI-R (5'-GGGC ATGCTTTTGCACATGGCAG-3') were used to change the amino acid Arg182 to Lys182 (underlined) and to include two nucleotide mutations (bold) to generate a unique BamHI restriction site. The other single mutations were produced similarly. The mutated PCR fragments were digested with SphI, and the resulting fragments were used to replace the wild-type HC-Pro region of the p35STuMVGFP to generate recombinant viruses (Fig. 1A). The recombinant viruses are named Tu-GX, in which $\mathrm{X}$ refers to the introduced amino acid (Fig. 1A).
Challenge inoculation with recombinant viruses and cross-protection assays.

All recombinant viruses were propagated from DNA-infectious clones. Aliquots of $1 \mu \mathrm{g}$ of DNA in sterilized water $(20 \mu \mathrm{l})$ were applied onto Carborundum-dusted leaves of Chenopodium quinoa with a sterilized glass spatula. At 6 dpi, establishment of infection of each recombinant virus on the inoculated leaves was examined based on GFP signal under a fluorescent microscope. The virus was then isolated from a single lesion and transferred to $N$. benthamiana plants for amplification and evaluation of viral pathogenicity at $7 \mathrm{dpi}$. Twenty $N$. benthamiana plants were used for each experiment. Results from triplicates of each experiment were used to make conclusions.

In cross-protection assays, Tu-GK was used as the protective virus and YC5 was used as the challenge virus. The 2.5-weekold Arabidopsis seedlings were mechanically inoculated with Tu-GK, which was prepared from $0.5 \mathrm{~g}$ of infected $N$. benthamiana leaves using $2 \mathrm{ml}$ of $0.01 \mathrm{M}$ sodium phosphate buffer, pH 7.2. At 7 days after the protective virus inoculation, two fully expanded leaves of a plant were mechanically challenged with YC5, which was prepared from $0.5 \mathrm{~g}$ of $N$. benthamiana leaves using $2 \mathrm{ml}$ of $0.01 \mathrm{M}$ sodium phosphate buffer, $\mathrm{pH}$ 7.2. The protection was evaluated by examining the development of symptoms in the plants. The presence of challenge virus was monitored by indirect ELISA and real-time RT-PCR at 14 days after challenge inoculation, as described below.

\section{Transgenic Arabidopsis \\ for P1/HC-Pro ${ }^{\mathrm{R}}$ and P1/HC-Pro ${ }^{\mathrm{K}}$ expression. $^{\text {X }}$}

The $P 1 / H C-P r o^{R}$ and $P 1 / H C$-Pro ${ }^{K}$ fragments were amplified from the Tu-GR- and Tu-GK-infectious clones, respectively, by PCR with primer pair PTuP1-Nco (5'-GCGCCATGGCAG TAGTTACATTCGCATCGGCT-3') and MTuHC-Pac (5'-CTA GTTAATTAATTATCCGACACGGTAGTGTTTTAAGCT-3'), which contain $N c o$ I and $P a c I$ (underlined), respectively, and cloned into the $\mathrm{pBCo}$ vector (Wu et al. 2010) to generate $\mathrm{pBCo}-\mathrm{P} 1 / \mathrm{HC}^{\mathrm{R}}$ and $\mathrm{pBCo}-\mathrm{P} 1 / \mathrm{HC}^{\mathrm{K}}$, respectively. The $\mathrm{pBCo}$ binary vector contains a double $35 \mathrm{~S}$ promoter to express the Pl/HC-Pro coding sequence.

Plants of the Arabidopsis L1 line (Elmayan et al. 1998), which carries a silenced GUS gene, were transformed with the above binary vectors via a floral-dip method (Clough and Bent 1998; Zhang et al. 2006). Seed from the infiltrated plants were selected on standard Murashige and Skoog medium (Murashige and Skoog 1962) containing the appropriate selective agents. The growth and developmental phenotypes were analyzed for T2 transformants.

\section{Confocal microscopy.}

GFP fluorescence at $10 \mathrm{dpi}$ of Tu-GR- or Tu-GK-infected Arabidopsis leaves was monitored using a Leica TCS SP5 II confocal laser-scanning microscope that was equipped with a multiline argon laser and a filter set for a GFP fluorescence filter (excitation filter Acousto-optic Tunable filter 488, emission bandwidth 496 to $574 \mathrm{~nm}$ ). All images were obtained with PMT2 offset (-1.0)/grain (895.3), and graphically arranged using Adobe Photoshop CS3 software (Adobe Systems Inc., Mountain View, CA, U.S.A.). The GFP fluorescence intensity was calculated by LAS AF (Leica, Ryswyck, The Netherlands).

\section{ELISA.}

Nine leaf disks, approximately $0.5 \mathrm{~cm}$ each in diameter, were punched from three different upper leaves of each infected plant at $0,5,10,15$, and $20 \mathrm{dpi}$. The disks from each plant were combined into triplicate samples and assayed by indirect ELISA using anti-TuMV CP antiserum as the primary 
antibody (Lin et al. 2013). The results were recorded as absorbance at $405 \mathrm{~nm}$ using a VersaMax Tunable Microplate Reader (Molecular Devices, Sunnyvale, CA, U.S.A.).

\section{Real-time RT-PCR.}

Total RNA was extracted from $0.1 \mathrm{~g}$ of plant tissue using Trizol reagent (Invitrogen, Carlsbad, CA, U.S.A.). RT was performed using the SuperScript III first-strand synthesis system (Invitrogen) following the manufacturer's instructions. Realtime PCR was performed using a LightCycler 480 instrument (Roche, Indianapolis, IN, U.S.A.) using three sets of primers: PGFP (5'-GGACGAGCTGTACAAGGCTA-3') and MTuCP1 (5'-TTTGCCTCTCTCGTTCCTTT- $3^{\prime}$ ) for the amplification of the GFP/CP region of Tu-GR or Tu-GK, PTuNIb (5'-AAGGA ACCAGCTCAAGAGGA- $3^{\prime}$ ) and MTuCP1 for the amplification of the $\mathrm{NIb} / \mathrm{CP}$ region of YC5, and UBQ-F1 (5'-CACTTC ACTTGGTCTTGCGT-3'); and UBQ-R1 (5'-TATCCTGGATC TTGGCCTTC- $3^{\prime}$ ) for the detection of the ubiquitin gene. The Tu-GR, Tu-GK, YC5, and ubiquitin transcripts were quantified via a relative cycle threshold $(\mathrm{Ct})$ method. The primers for analyzing the expression of SA-dependent and -independentassociated genes were the same as those reported by Ho and associates (2013). All experiments were performed with three independent replicates to compensate for possible loading errors. The relative expression levels were calculated based on the $\Delta \Delta \mathrm{Ct}$ value, and each sample was normalized according to the expression levels of ubiquitin. At 0 and 5 dpi for the viral RNA level evaluation, the virus-inoculated leaves were collected for detecting the host genes. At $10 \mathrm{dpi}$, the systemic leaves of the virus-infected plants were collected for detection.

\section{High-throughput deep sequencing of small RNAs.}

The small RNA profiles in Tu-GR- and Tu-GK-infected Arabidopsis Col-0 and $d c l 2 / 4$ plants were analyzed by deep sequencing. Total RNA was extracted from TuMV-infected plants with Trizol (Invitrogen) at $15 \mathrm{dpi}$, following the manufacturer's protocols, and $10 \mu \mathrm{g}$ of total RNA from each sample was used to generate small RNA libraries for sequencing with Illumina HigSeq2000 by Genomics BioSci \& Tech Co. A high-throughput data analysis was performed using the CLC Genome Workbench 5.1.

The total reads for each sample underwent quality trimming and size selection $(21,22$, and $24 \mathrm{nt})$. The read counts for the selected samples of size $k$ (Fig. 3E) were calculated using the following formula: total reads for the sample of size $k /$ (total reads for $d c l 2 / 4$ plants/total reads for Col-0 plants).

The denominator of the above formula was used to adjust for different throughput numbers under two conditions. The reads per kilobase of exon model per million mapped reads (RPKM) values for the selected samples of size $k$ (Fig. 3E) were calculated using the following equation: $\mathrm{RPKM}=10^{9} \times$ [(total sample reads)/(total reads of size $k$ )/ $k$ ].

To test whether the total number of reads for a given sample was significantly different from that for the Col-0 plant, we performed a two-sample Poisson test using the "poisson.test" function in the $\mathrm{R}$ software package ( $\mathrm{R}$ Development Core Team 2012). The significance parameters based on the Poisson test $P$ values are marked in Figure 4A.

\section{ACKNOWLEDGMENTS}

This study was supported by the National Science Council (NSC) 1002313-B-005-009-MY3 to S.-D. Yeh; NSC 97-2321-B-002-046, NSC-982313-B-002-047-MY3, and NSC 100-2923-B-002-001-MY3 and National Taiwan University (1023R7602B2) to S.-S. Lin; and also by DUPONT to N.-H. Chua. Y.-J. Kung was supported by a postdoctoral fellowship from NSC (NSC 101-2911-I-005-301 and NSC 102-2911-I-005-301). S.-S. Lin, S.-D. Yeh, C.-P. Lin, and N.-H. Chua designed the research methods. Y.-J.
Kung, P.-C. Lin, S.-F. Hong, Y.-H. Huang, H.-W. Wu, and C.-C. Chen performed the experiments. L.-Y. Liu performed statistical assays on the deep sequence data. All of the authors discussed the results and commented on the manuscript, which was written by S.-S. Lin.

\section{LITERATURE CITED}

Bouché, N., Lauressergues, D., Gasciolli, V., and Vaucheret, H. 2006. An antagonistic function for Arabidopsis DCL2 in development and a new function for DCL4 in generating viral siRNAs. EMBO (Eur. Mol. Biol. Organ.) J. 25:334-3356.

Chen, C. C., Chao, C. H., Chen, C. C., Yeh, C. C., Tsai, H. T., and Chang, C. A. 2003. Identification of Turnip mosaic virus isolates causing yellow stripe and spot on calla lily. Plant Dis. 87:901-905.

Clough, S. J., and Bent, A. F. 1998. Floral dip: A simplified method for Agrobacterium-mediated transformation of Arabidopsis thaliana. Plant J. 16:735-743.

Deleris, A., Gallego-Bartolome, J., Bao, J., Kasschau, K. D., Carrington, J. C., and Voinnet, O. 2006. Hierarchical action and inhibition of plant Dicer-like proteins in antiviral defense. Science 313:68-71.

Derrien, B., Baumberger, N., Schepetilnikov, M., Viotti, C., De Cillia, J., Ziegler-Graff, V., Isono, E., Schumacher, K., and Genschik, P. 2012. Degradation of the antiviral component ARGONAUTE1 by the autophagy pathway. Proc. Natl. Acad. Sci. U.S.A. 109:15942-15946.

Eamens, A., Wang, M. B., Smith, N. A., and Waterhouse, P. M. 2008. RNA silencing in plants: Yesterday, today, and tomorrow. Plant Physiol. 147:456-468.

Elmayan, T., Balzergue, S., Béon, F., Bourdon, V., Daubremet, J., Guénet, Y., Mourrain, P., Palauqui, J. C., Vernhettes, S., Vialle, T., Wostrikoff, K., and Vaucheret, H. 1998. Arabidopsis mutants impaired in cosuppression. Plant Cell 10:1747-1758.

English, J. J., Mueller, E., and Baulcombe, D. C. 1996. Suppression of virus accumulation in transgenic plants exhibiting silencing of nuclear genes. Plant Cell 8:179-188.

Gal-On, A. 2000. A point mutation in the FRNK motif of the potyvirus helper component-protease gene alters symptom expression in cucurbits and elicits protection against the severe homologous virus. Phytopathology 90:467-473.

Gal-On, A., and Shiboleth, Y. M. 2006. Cross-Protection. Pages 261-287 in: Natural Resistance Mechanisms of Plants to Viruses. G. Loebenstein and J. P. Carr, eds. Springer, Dordrecht, The Netherlands.

Garcia-Ruiz, H., Takeda, A., Chapman, E. J., Sullivan, C. M., Fahlgren, N., Brempelis, K. J., and Carrington, J. C. 2010. Arabidopsis RNAdependent RNA polymerases and dicer-like proteins in antiviral defense and small interfering RNA biogenesis during Turnip mosaic virus infection. Plant Cell 22:481-496.

Gibbings, D., Mostowy, S., Jay, F., Schwab, Y., Cossart, P., and Voinnet, O. 2012. Selective autophagy degrades DICER and AGO2 and regulates miRNA activity. Nat. Cell Biol. 14:1314-1321.

Hellwald, K. H., and Palukaitis, P. 1995. Viral RNA as a potential target for two independent mechanisms of replicase-mediated resistance against cucumber mosaic virus. Cell 83:937-946.

Ho, Y. P., Tan, C. M., Li, M. Y., Lin, H., Deng, W. L., and Yang, J. Y. 2013. The AvrB_AvrC domain of AvrXccC of Xanthomonas campestris pv. campestris is required to elicit plant defense responses and manipulate ABA homeostasis. Mol. Plant-Microbe Interact. 26:419-430.

Hofius, D., Maier, A. T., Dietrich, C., Jungkunz, I., Börnke, F., Maiss, E., and Sonnewald, U. 2007. Capsid protein-mediated recruitment of host DnaJ-like proteins is required for Potato virus $Y$ infection in tobacco plants. J. Virol. 81:11870-11880.

Jovel, J., Walker, M., and Sanfaçon, H. 2011. Salicylic acid-dependent restriction of Tomato ringspot virus spread in tobacco is accompanied by a hypersensitive response, local RNA silencing, and moderate systemic resistance. Mol. Plant-Microbe Interact. 24:706-718.

Kasschau, K. D., Xie, Z., Allen, E., Llave, C., Chapman, E. J., Krizan, K. A., and Carrington, J. C. 2003. P1/HC-Pro, a viral suppressor of RNA silencing, interferes with Arabidopsis development and miRNA unction. Dev. Cell 4:205-207.

Kim, B., Masuta, C., Matsuura, H., Takahashi, H., and Inukai, T. 2008. Veinal necrosis induced by Turnip mosaic virus infection in Arabidopsis is a form of defense response accompanying HR-like cell death Mol. Plant-Microbe Interact. 21:260-268.

Lellis, A. D., Kasschau, K. D., Whitham, S. A., and Carrington, J. C. 2002. Loss-of-susceptibility mutants of Arabidopsis thaliana reveal an essential role for eIF(iso)4E during potyvirus infection. Curr. Biol. 12:10461051.

Lin, S. S., Henriques, R., Wu, H. W., Niu, Q. W., Yeh, S. D., and Chua, N. H. 2007a. Strategies and mechanisms of plant virus resistance. Plant Biotechnol. Rep. 1:125-134. 
Lin, S. S., Wu, H. W., Jan, F. J., Hou, R. F., and Yeh, S. D. 2007b. Modifications of the HC-Pro of Zucchini yellow mosaic potyvirus for generation of attenuated mutants for cross protection against severe infection. Phytopathology 97:287-296.

Lin, S. S., Martin, R., Mongrand, S., Vandenabeele, S., Chen, K. C., Jang, I. C., and Chua, N. H. 2008. RING1 E3 ligase localizes to plasma membrane lipid rafts to trigger FB1-induced programmed cell death in Arabidopsis. Plant J. 56:550-561.

Lin, S. S., Wu, H. W., Elena, S.F., Chen, K. C., Niu, Q. W., Yeh, S. D. Chen, C. C., and Chua, N. H. 2009. Molecular evolution of a viral noncoding sequence under the selective pressure of amiRNA-mediated silencing. PLoS Pathog. 5:e1000312. Published online.

Lin, Y. Y., Fang, M. M., Lin, P. C., Chiu, M. T., Liu, L. Y., Lin, C. P., and Lin, S. S. 2013. Improving initial infectivity of the Turnip mosaic virus (TuMV) infectious clone by an mini binary vector via agro-infiltration. Bot. Stud. 54:22

Love, A. J., Geri, C., Laird, J., Carr, C., Yun, B. W., Loake, G. J., Tada, Y., Sadanandom, A., and Milner, J. J. 2012. Cauliflower mosaic virus protein P6 inhibits signaling responses to salicylic acid and regulates innate immunity. PLoS One 7:e47535. Published online.

Lu, B., Stubbs, G., and Culver, J. N. 1988. Coat protein interactions involved in tobacco mosaic tobamovirus cross-protection. Virology 248:188-198.

McKinney, H. H. 1929. Mosaic diseases in the Canary Islands, West Africa and Gibraltar. J. Agric. Res. 39:557-578.

Mishina, T. E., and Zeier, J. 2006. The Arabidopsis flavin-dependent monooxygenase FMO1 is an essential component of biologically induced systemic acquired resistance. Plant Physiol. 2006:1666-1675.

Moissiard, G., Parizotto, E.A., Himber, C., and Voinnet, O. 2007. Transitivity in Arabidopsis can be primed, requires the redundant action of the antiviral Dicer-like 4 and Dicer-like 2, and is compromised by viralencoded suppressor proteins. RNA 13:1268-1278.

Morel, J. B., Godon, C., Mourrain, P., Béclin, C., Boutet, S., Feuerbach, F., Proux, F., and Vaucheret, H. 2002. Fertile hypomorphic ARGONAUTE (ago1) mutants impaired in post-transcriptional gene silencing and virus resistance. Plant Cell 14:629-639.

Morlando, M., Ballarino, M., Gromak, N., Pagano, F., Bozzoni, I., and Proudfoot, N. J. 2008. Primary microRNA transcripts are processed cotranscriptionally. Nat. Struct. Mol. Biol. 15:902-909.

Murashige, T., and Skoog, F. 1962. A revised medium for rapid growth and bioassays with tobacco tissue cultures. Physiol. Plant. 15:473-497.

Nakahara, K. S., Masuta, C., Yamada, S., Shimura, H., Kashihara, Y., Wada, T. S., Meguro, A., Goto, K., Tadamura, K., Sueda, K., Sekiguchi, T., Shao, J., Itchoda, N., Matsumura, T., Igarashi, M., Ito, K., Carthew, R. W., and Uyeda, I. 2012. Tobacco calmodulin-like protein provides secondary defense by binding to and directing degradation of virus RNA silencing suppressors. Proc. Natl. Acad. Sci. U.S.A. 109:1011310118.

Nawrath, C., Heck, S., Parinthawong, N., and Métraux, J. P. 2002. EDS5, an essential component of salicylic acid-dependent signaling for disease resistance in Arabidopsis, is a member of the MATE transporter family. Plant Cell 14:275-286.

Nguyen, L., Lucas, W. J., Ding, B., and Zaitlin, M. 1996. Viral RNA trafficking is inhibited in replicase-mediated resistant transgenic tobacco plants. Proc. Natl. Acad. Sci. U.S.A. 93:12643-11267.

Niu, Q. W., Lin, S. S., Reyes, J. L., Chen, K. C., Wu, H. W., Yeh, S. D., and Chua, N. H. 2006. Expression of artificial microRNAs in transgenic Arabidopsis thaliana confers virus resistance. Nat. Biotechnol. 24:1420-1428.

Osbourn, J. K., Sarkar, S., and Wilson, T. M. 1990. Complementation of coat protein-defective TMV mutants in transgenic tobacco plants expressing TMV coat protein. Virology 179:921-925.

Pasin, F., Simón-Mateo, C., and García, J. A. 2014. The hypervariable amino-terminus of $\mathrm{P} 1$ protease modulates potyviral replication and host defense responses. PLoS Pathog. 10:e1003985. Published online.

Prins, M., and Goldbach, R. 1996. RNA-mediated virus resistance in transgenic plants. Arch. Virol. 141:2259-2276.

R Development Core Team. 2012. R: A language and environment for statistical computing. R Foundation for Statistical Computing. Vienna.

Rakhshandehroo, F., Takeshita, M., Squires, J., and Palukaitis, P. 2009. The influence of RNA-dependent RNA polymerase 1 on potato virus Y infection and on other antiviral response genes. Mol. Plant-Microbe Interact. 22:1312-1318.

Ratcliff, F., Harrison, B. D., and Baulcombe, D. C. 1997. A similarity between viral defense and gene silencing in plants. Science 276:15581560

Register, J. C., III, and Beachy, R. N. 1988. Resistance to TMV in transgenic plants results from interference with an early event in infection. Virology 166:524-532.

Ruiz, M. T., Voinnet, O., and Baulcombe, D. C. 1998. Initiation and maintenance of virus-induced gene silencing. Plant Cell 10:937-946.

Shiboleth, Y. M., Haronsky, E., Leibman, D., Arazi, T., Wassenegger, M., Whitham, S. A., Gaba, V., and Gal-On, A. 2007. The conserved FRNK box in HC-Pro, a plant viral suppressor of gene silencing, is required for small RNA binding and mediates symptom development. J. Virol $81: 13135-13148$

Simón-Mateo, C., and García, J. A. 2011. Antiviral strategies in plants based on RNA silencing. Biochim. Biophys. Acta 1809:722-731.

Wang, G. F., Seabolt, S., Hamdoun, S., Ng, G., Park, J., and Lu, H. 2011a. Multiple roles of WIN3 in regulating disease resistance, cell death, and flowering time in Arabidopsis. Plant Physiol. 156:1508-1519.

Wang, X. B., Jovel, J., Udomporn, P., Wang, Y., Wu, Q., Li, W. X., Gasciolli, V., Vaucheret, H., and Ding, S. W. 2011b. The 21-nucleotide, but not 22-nucleotide, viral secondary small interfering RNAs direct potent antiviral defense by two cooperative argonautes in Arabidopsis thaliana. Plant Cell 23:1625-1638.

Wildermuth, M. C., Dewdney, J., Wu, G., and Ausubel, F. M. 2001. Isochorismate synthase is required to synthesize salicylic acid for plant defence. Nature 414:562-565.

Wu, H. W., Lin, S. S., Chen, K. C., Yeh, S. D., and Chua, N. H. 2010. Discriminating mutations of HC-Pro of Zucchini yellow mosaic virus with differential effects on small RNA pathways involved in viral pathogenicity and symptom development. Mol. Plant-Microbe Interact. 23:1728

Yang, S. J., Carter, S. A., Cole, A. B., Cheng, N. H., and Nelson, R. S. 2004. A natural variant of a host RNA-dependent RNA polymerase is associated with increased susceptibility to viruses by Nicotiana benthamiana. Proc. Natl. Acad. Sci. U.S.A. 101:6297-6302.

Zhang, X., Henriques, R., Lin, S. S., Niu, Q. W., and Chua, N. H. 2006. Agrobacterium-mediated transformation of Arabidopsis thaliana using the floral dip method. Nat. Protocols 1:641-646.

Zhou, N., Tootle, T. L., Tsui, F., Klessig, D. F., and Glazebrook, J. 1998. PAD4 functions upstream from salicylic acid to control defense responses in Arabidopsis. Plant Cell 10:1021-1030.

Zhu, S., Jeong, R. D., Venugopal, S. C., Lapchyk, L., Navarre, D., Kachroo, A., and Kachroo, P. 2011. SAG101 forms a ternary complex with EDS1 and PAD4 and is required for resistance signaling against turnip crinkle virus. PLoS Pathog. 7:e1002318. Published online.

Ziebell, H., and Carr, J. P. 2009. Effects of dicer-like endoribonucleases 2 and 4 on infection of Arabidopsis thaliana by cucumber mosaic virus and a mutant virus lacking the $2 \mathrm{~b}$ counter-defence protein gene. J. Gen. Virol. 90:2288-2292.

Ziebell, H., and Carr, J. P. 2010. Cross-protection: A century of mystery. Adv. Virus Res. 76:211-264.

Ziebell, H., Payne, T., Berry, J. O., Walsh, J. A., and Carr, J. P. 2007. A cucumber mosaic virus mutant lacking the $2 \mathrm{~b}$ counter-defence protein gene provides protection against wild-type strains. J. Gen. Virol. $88: 2862-2871$ 